\title{
Las facultades colegislativas de los gobernadores en el constitucionalismo subnacional argentino*
}

\author{
Legislative PoWers of Governors in the ARgentine Subnational Constitutionalism
}

CRISTIAN ALTAVILLA*

\section{RESUMEN}

De acuerdo a Mainwaring y Shugart (2002), los poderes ejecutivos en un sistema presidencialista pueden ser clasificados en fuertes y débiles a partir de dos variables: los poderes partidarios y los poderes de legislación. Ambos se refieren a la habilidad de los ejecutivos de implementar políticas públicas y en particular a su relación con el poder legislativo, en tanto principal instancia de decisión de políticas públicas.

El presente trabajo intenta llevar los términos de la discusión al análisis comparativo al nivel subnacional en Argentina. Con este objetivo en mente, se analizarán los poderes legislativos conferidos a los poderes ejecutivos por las constituciones provinciales en un análisis comparativo de las 24 jurisdicciones provinciales. El objetivo del trabajo es determinar con qué poderes legislativos cuentan los gobernadores y en función de ello determinar el grado de fortaleza o debilidad dentro de la estructura institucional formal-constitucional.

\section{PALABRAS CLAVE}

Gobiernos subnacionales, gobernadores, poderes de legislación

\section{ABSTRACT}

According to Mainwaring and Shugart (2002), executive powers within a presidential system may be classified in strong or weak from two variables: partisan powers and legislative powers. Both referring to the ability of executive branch to implement public policies and in particular to it relation with the legislative branch, since this is the main instance responsible for policy decision.

This paper attempts to bring the terms of the debate on a comparative analysis at the subnational level in Argentina. With this aim in mind, the legislative powers of executive branches conferred by the provincial constitutions will be analyzed in a 24 provincial jurisdictions comparative perspective. The objective of this paper is to determine the legislative powers available for governors and, according to that, determine the degree of strength or weakness within the institutional formal-constitutional structure.

\footnotetext{
* Una primera versión preliminar de este trabajo fue presentada como ponencia en el XII Congreso Nacional de Ciencia Política: "La Política en Balance: Debates y Desafíos Regionales", organizado por la SAAP (Sociedad Argentina de Análisis Político) y la Un iversidad Nacional de Cuyo, Mendoza, 12 al 15 de agosto de 2015. Este trabajo es el resultado de un proyecto de investigación realizado con la colaboración de Emilia Ferreyra, Federico Ortega y María Fernanda Díaz Peralta, alumnos de la Carrera de Abogacía de la Universidad Nacional de Córdoba y ayudantes alumnos de la materia Derecho Público Provincial y Municipal, Cátedra A (2014 y 2015), en las tareas de recolección y recopilación de los datos necesarios para llevar adelante el presente trabajo.

${ }^{* *}$ Abogado, Doctor en Derecho y Cs Ss, Universidad Nacional de Córdoba (UNC) y PhD Visiting en la Universidad de Bologna, Italia; Profesor de la materia Derecho Público Provincial y Municipal y de la materia Derecho Político, Facultad de Derecho - UNC y de la Universidad Siglo 21, Córdoba, Argentina. Becario Postdoctoral de CONICET, y visiting researcher en la Universidad Federal de Minas Gerais, Belo Horizonte, Brasil (con beca de AUGM), en la Aarhus Universitet, Dinamarca (con beca del Grupo Coimbra) y en la Universidad de Granada (beca AUIP). Director del proyecto de investigación internacional "Relaciones intergubernamentales, descentralización fiscal y gobiernos multinivel. España y Argentina en perspectiva comparada (1970-2018)" radicado en la Universidad Siglo 21 y miembro investigador del proyecto "Meta-requisitos, instituciones y prácticas de la Democracia Local" radicado en la Facultad de Ciencias Políticas y Relaciones Internacionales de la Universidad Católica de Córdoba y del proyecto "La Actuación Judicial ante la tensión Público-Privado", radicado en el Centro de Investigaciones Jurídicas y Sociales (CIJS). E-mail: cristianaltavilla@hotmail.com.
} 


\section{KEYWORDS}

Subnacional Governments, governors, legislative powers

\section{Introducción}

Las 23 provincias argentinas, sumada a ellas la Ciudad Autónoma de Buenos Aires (CABA), en el ejercicio de su poder constituyente autónomo optaron unánimemente por forma de gobierno el régimen presidencialista. De acuerdo a lo prescripto por los arts. 5 y 122 de la Constitución Nacional (CN), las provincias son libres de crear sus propias instituciones, siempre que respeten la forma representativa y republicana de gobierno. Ello deja un amplio margen de autonomía para optar por diversas formas de gobierno (presidencialista, parlamentarista, semipresidencialista, etc.). A partir de la sanción de la Constitución Nacional en 1853, todas las provincias optaron por la forma representativa republicana con un régimen presidencialista ${ }^{1}$, con la clásica división tripartita de poderes en legislativo, ejecutivo y judicial. Todas ellas erigen un poder ejecutivo unipersonal a cargo de un ciudadano con el título de gobernador con una serie de atribuciones contenida en un capítulo especial dentro del texto constitucional provincial. La ciudad de Buenos Aires, por su especial estatus autonómico, cuenta con un jefe de gobierno (Art. 129, CN), aunque en los hechos la figura se asimila a la de un gobernador de provincia.

El sistema presidencial se caracteriza por la independencia del poder ejecutivo respecto del legislativo en lo tocante a su forma de designación. Desde que el presidente - un único individuo a cargo del Ejecutivo- es electo directa o indirectamente por el electorado (por voto popular directo o por medio de colegios electorales), la diferencia substancial con los regímenes parlamentaristas radica en que en estos el poder ejecutivo (normalmente denominado primer ministro) es elegido por el propio parlamento, de cuya autoridad depende. En los sistemas presidencialistas, en cambio, la elección del presidente independiente de los restantes poderes, sumado a ello un término fijo de su mandato, hacen de este la figura prominente y gravitante del sistema político. Aun cuando las constituciones explícitamente se adhieran al principio de la división de poderes y al sistema de pesos y contrapesos, algunas cláusulas constitucionales dotan al ejecutivo de ciertas herramientas que reafirman su figura protagónica en el escenario político.

Este ha sido típicamente el caso en los países latinoamericanos ${ }^{2}$. Desde las primeras constituciones nacionales en América Latina, el diseño constitucional estuvo orientado a moldear una figura ejecutiva fuerte, con herramientas suficientes incluso para sobreponerse por sobre el poder legislativo. Un cabal y explícito ejemplo de ello lo encontramos en las Bases y Puntos de Partida para la Organización Política de la República Argentina de Juan Bautista ALBERDI cuando sostenía que el destino de América Latina estaba en manos del poder ejecutivo: "Yo no vacilaría en asegurar que de la constitución del poder ejecutivo, especialmente, depende la suerte de los Estados de la América del Sur"; y más adelante agrega: "Dad al poder ejecutivo el poder posible, pero dádselo por medio de una constitución" 3 .

Las actuales constituciones latinoamericanas continúan erigiendo un presidente fuerte ${ }^{4}$. A nivel subnacional, las provincias argentinas adoptaron para sí un régimen presidencialista, con un poder ejecutivo a cargo de un ciudadano con el título de gobernador y un poder legislativo comúnmente denominado legislatura. Ambos poderes cuentan con un término fijo de duración y son electos directamente por el pueblo de forma independiente, aunque en la mayoría de los

\footnotetext{
${ }^{1}$ La CABA es la única jurisdicción subnacional que por imperio de la propia constitución nacional tiene asignado un régimen presidencialista (véase art. 129, CN).

${ }^{2}$ NEGRETTO (2013), GARGARELLA (2014).

${ }^{3}$ ALBERDI (1994), p. 182.

${ }^{4}$ MAINWARING y SHUGART (2002).
} 
casos las elecciones a ambos cargos son simultáneas ${ }^{5}$. Si bien originariamente el poder ejecutivo fue pensado como un poder del Estado encargado de la ejecución de las decisiones del poder legislativo, la máxima instancia de representación popular, a lo largo de los siglos se fue convirtiendo en la principal figura del escenario político, siendo en la actualidad el poder que no solo implementa prácticamente todas las políticas estatales (a diferencia de lo que sucede en EEUU, por ejemplo, donde el Congreso tiene a su cargo la ejecución de muchas e importantes partidas presupuestarias), sino también el que las propone.

A continuación, el trabajo se estructura de la siguiente manera: en el siguiente apartado se realizarán algunas consideraciones concernientes al marco teórico y la metodología empleada, prestando particular atención al estado del arte en el estudio de los gobiernos subnacionales; en el siguiente apartado se analizarán los seis indicadores identificados en el derecho público provincial argentino como poderes de legislación del poder ejecutivo; en el apartado IV se presenta un índice que mide cuantitativamente los distintos poderes de legislación en orden a determinar su importancia en el proceso legislativo, estandarizar criterios de clasificación y comprar entre los distintos sistemas constitucionales subnacionales.

\section{Encuadre teórico y metodología de la investigación}

En las últimas décadas trabajos relacionados con la política subnacional comenzaron a proliferar. En un primer momento, esta literatura comenzó a interesarse a raíz del impacto que la política subnacional producía sobre el sistema político nacional que comienza a ser observado por los estudiosos en temas tales como las finanzas públicas ${ }^{6}$ y los sistemas de partidos y electorales ${ }^{7}$. Estos primeros estudios comienzan a poner de resalto la importancia no tanto del nivel subnacional en sí, sino más precisamente de los gobernadores en el contexto de la federación argentina ${ }^{8}$. Una segunda generación de estudios subnacionales comienza a interesarse por la política subnacional en sí misma, y la analiza tanto desde su importancia dentro de la federación en términos más generales ${ }^{9}$, como a través de temas más puntuales, tales como la reelección de los gobernadores ${ }^{10}$, sobre reformas e innovaciones constitucionales ${ }^{11}$, sobre cuestiones electorales ${ }^{12}$, una prolífica literatura sobre relaciones fiscales intergubernamentales ${ }^{13}$, así como interesantes e innovadores estudios acerca de la calidad democrática de las provincias argentinas ${ }^{14}$.

A pesar de estos avances, la literatura local, tanto la constitucionalista desde las ciencias jurídicas, como las distintas perspectivas analíticas de las ciencias políticas, han profundizado el estudio sobre los poderes ejecutivos provinciales hacia el interior de sus provincias; la mayoría de los estudios consideran la realidad subnacional en relación con (o dependiente de) la realidad política nacional y ninguno se ha centra en los aspectos constitucionales de la estructura política de las unidades subnacionales en Argentina. Más específicamente, no existen trabajos que analicen los poderes de legislación de los gobernadores. Para superar este estadio, resulta necesario el análisis de los sistema políticos provinciales como sistemas independientes que se constituyan como el principal objeto de estudio. Por su parte, los manuales de la asignatura Derecho Público Provincial se limitan a un análisis descriptivo de la norma, desde una perspectiva jurídica-dogmática que se circunscribe al mero análisis de la norma o, en el mejor de los casos, a la comparación de normas entre constituciones provinciales.

\footnotetext{
${ }^{5}$ La última provincia en incorporar la elección directa de su gobernador, reemplazando al sistema de colegio electoral, fue la provincia de Corrientes en la reforma constitucional de 1993.

${ }^{6}$ SAWERS (1996) y JONES et al. (1997) y (2000).

7 JONES (1998 y 2002), BENTON (2003), LEIRAS (2010) OLMEDA y SUÁREZ (2007).

8 JONES Y HWANG (2005).

${ }^{9}$ SUÁREZ (2011).

${ }^{10}$ ALMARAZ (2010), CAEDARELLO (2012), ALTAVILLA (2017).

${ }^{11}$ SUÁREZ (2001).

12 CALVO y MICOZZI (2005), CALVO y ESCOLAR (2005), ESCOLAR (2011)

13 BONVECCHI Y LODOLA (2011), LANDON (2003), OLMEDA (2009), SAIEGH y TOMMASI (1998, 1999), ALTAVILLA (2016).

${ }^{14}$ GERVASONI (2010a, 2010b y 2011), GIRAUDY (2011)
} 
Desde antaño, se sostuvo que en Argentina, tanto a nivel nacional como provincial, los poderes ejecutivos ejercían un poder exorbitante en la arena política, identificándolos con los cacicazgos del siglo XIX ${ }^{15}$. Sin embargo, la mera (y apriorística) afirmación de que los presidentes y gobernadores son figuras fuertes no deja de ser intuitiva, ya que ninguno de aquellos trabajos ha testeado la fortaleza (o debilidad) de los poderes ejecutivos. En este sentido, el trabajo pretende contribuir en dos aspectos. En primer lugar, y a pesar de aquellas afirmaciones, se pretende medir la fortaleza de los poderes ejecutivos provinciales a partir de ciertos indicadores que la literatura ha elaborado en el estudio de los presidencialismos en el nivel nacional. En segundo lugar, realiza un estudio comparado de las 24 jurisdicciones subnacionales en Argentina en un análisis de las constituciones provinciales a fin de identificar el alcance y medida de tales poderes (tal cual se encuentran estos previstos desde el diseño institucional). En función de ello, se pretende contribuir en un tema poco analizado tanto en las ciencias jurídicas como en las ciencias políticas, propiciando al mismo tiempo un mayor diálogo interdisciplinario entre ambas disciplinas, a través de un análisis que parte del derecho constitucional con los aportes realizados desde distintas perspectivas analíticas de las ciencias políticas.

Si bien este trabajo se centra en los poderes ejecutivos provinciales de Argentina, pretende también contribuir con pautas de universalización de la hipótesis de trabajo y del soporte metodológico. En este sentido, las variables fueron construidas partiendo de los aportes del PNUD que analiza el contexto latinoamericano y se elaboraron tomando en cuenta diferentes hipótesis, tomadas de los diseños institucionales tanto nacionales como subnacionales, y además de utilizar hipótesis teóricas con el objetivo de universalizar el análisis, de modo que pueda ser utilizado para el análisis de otros sistemas y no quede constreñido solo a los sistemas constitucionales de las provincias argentinas.

Se trata asimismo de un trabajo descriptivo que busca medir la mayor o menor incidencia que los poderes ejecutivos subnacionales tienen en el proceso legislativo a partir de los poderes formales que las constituciones locales les reconocen, expresa o implícitamente. En este sentido, el presente trabajo constituye un avance de una investigación más amplia que busca determinar la fortaleza o debilidad de los poderes ejecutivos provinciales en Argentina desde el retorno de la democracia en diciembre de 1983 hasta la actualidad a partir de dos variables principales: los poderes de legislación y los poderes partidarios. El presente trabajo, sin embargo, se limitará a determinar los poderes de legislación como un primer paso en la investigación para determinar en un ulterior desarrollo de la investigación de qué manera estas variables legislativas interactúan con las partidarias para determinar el poder "real" de los gobernadores.

Para efectuar este análisis, se utilizará la clasificación de Mainwaring y Shugart para medir el poder de los presidentes sobre la formulación de políticas. Para estos autores, la "fortaleza" o "debilidad" de los poderes ejecutivos se relaciona directamente con la capacidad de "poner su propio sello sobre las políticas, o sea, para llevar a cabo su agenda" ${ }^{16}$. Lo que se considera, en definitiva, es el poder que tienen los ejecutivos sobre la formulación de políticas: "Hay dos medios principales a través de los cuales los presidentes pueden tener esa influencia. Uno es poseer poderes constitucionales inherentes al cargo de presidente que obliguen a que sus preferencias sean tomadas en consideración a la hora de aprobar las leyes. Otra es que tengan control sobre sus propios partidos y que éstos controlen una mayoría de escaños"17.

La primer variable constituye los poderes constitucionales sobre la legislación, es decir, poderes o herramientas institucionales conferidas por la constitución para hacer pesar su opinión en la formulación de políticas, sea para impulsar (poder proactivo) políticas deseadas, como para frenar (poder reactivo) políticas no queridas por el ejecutivo. La segunda variable son los poderes partidarios, y se traduce en dos aspectos: (a) en la posibilidad de controlar su propio

\footnotetext{
15 BIDEGAIN (1996), BIDART (1997), SAGÜÉS (2003a), entre otros.

${ }^{16}$ SHUGART Y MAINWARING (2002), p. 49.

17 SHUGART y MAINWARING (2002), p. 49.
} 
partido (es decir, que sea al mismo tiempo el líder partidario), y (b) que su partido controle la mayoría dentro del poder legislativo (gobierno unificado).

Ambas variables se relacionan directamente con la interacción del poder ejecutivo con el legislativo, en tanto este es la última instancia de decisión política -al menos de las más importantes y substanciales. A pesar de que en América Latina los poderes legislativos han jugado tradicionalmente un rol secundario ${ }^{18}$, tanto desde el diseño institucional como en la práctica, son estos los que en definitiva aprueban las políticas públicas a través de la sanción de leyes. Aun cuando en la práctica sean los poderes ejecutivos quienes formulen y decidan qué políticas aplicar, las mismas deben necesariamente ser convalidadas por el poder legislativo a través de leyes que formalmente deben sancionar.

La interacción entre ambas variables permite determinar la fortaleza o debilidad de los ejecutivos, es decir, el grado de influencia que tienen sobre las políticas y sobre los demás actores de la constelación. En cualquier sistema político en que ambas variables estén presentes, se podría predecir que estamos frente a un poder ejecutivo fuerte, capaz de implementar sus políticas deseadas y, al mismo tiempo, impedir aquellas no deseadas. También pueden ser utilizadas como variables explicativas de la permanencia en el cargo por períodos prolongados de tiempo.

El presente trabajo, sin embargo, se avocará exclusivamente a la determinación e identificación, dentro de las amplias competencias constitucionales, de a aquellas reconocidas por la literatura ${ }^{19}$ como facultades de legislación o poderes constitucionales de legislación de los gobernadores contenidos en las respectivas constituciones provinciales a los efectos de determinar el grado de fortaleza o debilidad dentro de la estructura institucional formal que proveen las constituciones locales, las que fueron identificadas en seis indicadores, según las respectivas atribuciones que tengan sobre el proceso legisferante.

Finalmente, el trabajo termina con algunas conclusiones que intentan realizar aportes a la literatura comparativista, desde que el marco teórico utilizado apunta a universalizar el análisis y, desde este punto de vista, no se limita solo a países con estructuras federales ni se circunscribe a sistemas subnacionales, ya que en el trabajo no se analiza el sistema federal (o una determinada constitución dada en el marco de un sistema político descentralizado), sino que lo que busca analizar son los propios textos constitucionales y cómo estos organizan sus poderes y, puntualmente, cuáles son las facultades colegislativas de los poderes ejecutivos. Partiendo de este esquema, el análisis busca ser aplicable a cualquier otro tipo de estructura constitucional (sea esta nacional, subnacional e incluso municipal). El trabajo se focaliza entonces en el diseño institucional en sí, ya que no se analiza la condicionalidad de ese diseño en un marco institucional más amplio (como sería el federal); se analiza en cambio el diseño institucional per se.

\section{Los poderes de legislación en las constituciones provinciales}

A continuación, el trabajo se estructura de acuerdo a seis indicadores que se han identificado para medir la fortaleza de los ejecutivos provinciales de acuerdo a sus poderes constitucionales de legislación (ver gráfico 1 en el anexo "Gráficos y Tablas").

Como lo indica el recuadro, los seis poderes en manos del ejecutivo hacen a su facultad de colegislador. Estos poderes sobre la legislación pueden ser utilizados, o bien para modificar el statu quo o bien para mantenerlo. En el primer caso, se tratará de un poder proactivo (un ejemplo típico lo constituyen los poderes de decreto), en cuyo caso, el ejecutivo aparece como iniciador "proactivo" del proceso de cambio legislativo, y el legislativo el actor "reactivo" 20 . En el segundo, se tratará de poderes reactivos, en tanto permiten al ejecutivo frenar proyectos

\footnotetext{
18 SAIEGH (2010), TOMMASI y SPILLER (2000), MUSTAPIC (2000).

19 MAINWARING y SHUGART (2002), PNUD (2004), PAYNE (2006), COLOMER y NEGRETTO (2003), entre otros.

${ }^{20}$ COLOMER Y NEGRETTO (2003).
} 
legislativos impulsados por sectores opositores que no son de su preferencia, como lo es el poder de veto ${ }^{21}$.

\subsection{Poderes de decreto}

Los poderes de decreto son típicamente poderes proactivos con que cuentan los poderes ejecutivos, en tanto les permite establecer un nuevo estatus quo. En el derecho constitucional argentino y en el derecho público provincial existen cinco tipos de decretos: (a) decretos autónomos, (b) de publicación o promulgación, (c) reglamentarios, (d) delegados y (e) de necesidad y urgencia ${ }^{22}$.

Para Shugart y Mainwaring, lo que ellos denominan el poder de decreto se circunscribe a la posibilidad del poder ejecutivo de establecer nueva legislación. De acuerdo a estos términos, estarían haciendo referencia a lo que la literatura constitucionalista argentina ha denominado decretos de necesidad y urgencia. Quedan excluidos, en consecuencia, los decretos regulatorios (o reglamentarios) para implementar la legislación sancionada por el poder legislativo; los decretos administrativos (o autónomos), a través de los cuales el poder ejecutivo ejerce su autoridad administrativa para reorganizar la administración pública y la burocracia; como así también el poder de emergencia, el cual - de acuerdo a la caracterización de los autores- es una autorización para "suspender ciertos derechos constitucionales bajo condiciones de catástrofe o desorden"23.

En este trabajo, sin embargo, se considerarán dentro del poder de decreto a los reglamentarios y de publicación, desde que en el derecho constitucional latinoamericano y argentino (nacional y provincial) adquieren ciertas características que dotan a los ejecutivos de un poder importante sobre la agenda legislativa, como veremos a continuación.

\subsubsection{Decretos autónomos}

De todos ellos, los autónomos son los que menos importancia revisten para medir los poderes del gobernador, en tanto los mismos no tienen incidencia en el proceso de formación y sanción de leyes. Los decretos autónomos forman parte de la autoridad regulatoria propia e inherente al poder ejecutivo, y son de naturaleza estrictamente administrativa. Todas las constituciones provinciales facultan al gobernador a emitir decretos para regir una materia en la que no hay normas legales aplicables (de ahí lo de "autónomo").

Se dictan para regir exclusivamente el funcionamiento interno de la administración ${ }^{24}$. A través de ellos, el gobernador designa a los funcionarios y empleados públicos, ordena la administración pública, reglamenta el empleo público, etc. Pero también a través de estos mismos decretos, los gobernadores han ejercido importantes facultades, tales como la creación de empresas provinciales estatales, de economía mixta y empresas de participación estatal mayoritaria.

\subsubsection{Decretos de promulgación y reglamentación}

Al igual que sucede en el orden federal y en el resto de los países latinoamericanos, los gobernadores de provincia cuentan con una importantísima facultad colegislativa: la de promulgar y reglamentar las leyes sancionadas por el poder legislativo.

Esta no es una facultad menor. Shugart y Mainwaring excluyen del poder de decreto de los presidentes a este tipo de decretos, que ellos denominan "decretos regulatorios (no legislativos)" 25 , sin dar mayores razones de la exclusión.

\footnotetext{
${ }^{21}$ SHUGART y MAINWARING (2002) p. 50.

22 BIDART (1997) p. 243; SAGÜÉS (2003a) p. 596; BIDEGAIN (1996), Tomo IV, p. 299 y Tomo III, parágrafo N.o 532.

${ }^{23}$ SHUGART y MAINWARING (2002) p. 56.

${ }^{24}$ GORDILLO (2013).

${ }^{25}$ SHUGART y MAINWARING (2002) p. 55.
} 
Pero en el derecho constitucional argentino, los decretos de ejecución o reglamentarios constituyen la etapa final del proceso de creación legislativa: una ley sancionada por el legislativo debe necesariamente ser promulgada y reglamentada por el Poder Ejecutivo (a diferencia de lo que sucede, por ejemplo, en EEUU). Esta facultad está prevista en todas las constituciones provinciales en idénticos términos que en la Constitución Nacional, cuyo art. 99, inc. $3^{\circ}$, otorga al presidente una verdadera facultad colegisferante. "Materialmente los decretos de ejecución importan una tarea de índole legislativa a cargo del presidente, sumamente importante - casi siempre decisiva - para la eficacia de la norma aprobada por el Congreso. Sin reglamentación, la ley queda habitualmente congelada y sin operatividad" ${ }^{26}$. Es decir que los gobernadores (al igual que el presidente en la esfera federal) cuentan con otro poder reactivo, el de dejar en suspenso los efectos de una ley al no dictar el respectivo decreto que la reglamenta, al no promulgarla o no publicarla (una ley no publicada nunca entraría en vigencia, conforme al art. 2으 del viejo Código Civil y art. 5 del nuevo Código Civil y Comercial de la Nación).

Nótese que se tratan de dos facultades distintas. La facultad de promulgar una ley, significa darla a conocer públicamente, sin cuyo paso una ley nunca entraría en vigencia, como dispone el Código Civil. En este sentido, un gobernador que no está conforme con una ley sancionada por el poder legislativo podría no publicarla y así enervar su vigencia y operatividad. La facultad de reglamentar una ley implica la potestad del gobernador de complementar las normas de la ley con otras sobre aspectos secundarios o accesorios ${ }^{27}$. Un importante número de leyes necesitan de reglamentación para que las mismas puedan entrar efectivamente en vigencia. Sea desde la disposición de medios materiales para que la ley sea aplicada o bien de reglamentaciones de tipo normativas que precisen el alcance de los términos de la ley. En este caso, si el poder ejecutivo no reglamenta una ley, esta también podría quedar inoperativa ${ }^{28}$.

Es necesario aclarar que la publicación de una ley así como su reglamentación no son facultades discrecionales en manos del ejecutivo, sino que constituyen un deber. La no publicación o reglamentación de una ley sancionada por el legislativo hace incurrir al gobernador en una falta grave, la que, desde el punto de vista de la responsabilidad penal, podría ser tipificada como violación de los deberes de los funcionarios públicos ${ }^{29}$. Desde el punto de vista de la responsabilidad política, la única solución posible que cabe es el juicio político, habilitando las causales de mal desempeño o comisión de delitos penales en el ejercicio de sus funciones. Una solución que resulta, sin embargo, demasiado extrema en relación a la falta.

Las constituciones provinciales han prefijado un determinado plazo (por lo general de 10 días hábiles) para que el ejecutivo ejerza su poder de veto, en caso contrario, el proyecto se tiene por promulgado. Esto es lo que el constitucionalismo denomina una promulgación tácita. Sin embargo, la promulgación tácita no subsana el efecto de la no publicación, un requisito sine qua non para que las leyes comiencen a producir efectos.

Son pocas las constituciones provinciales que prevén la posibilidad de su publicación por orden de la propia legislatura, en el caso de que el poder ejecutivo no ordenase su publicación en el boletín oficial. Un tercio de las constituciones provinciales prevén expresamente que los proyectos sancionados por el poder legislativo serán publicados por el poder ejecutivo luego de transcurridos diez días desde su remisión ${ }^{30}$, caso contrario se faculta a la legislatura a ordenar su publicación. Las restantes constituciones se limitan a establecer el instituto de la promulgación táctica, estableciendo que transcurrido un determinado plazo (en general, diez

\footnotetext{
${ }^{26}$ SAGÚÉS (2003a) p. 597.

27 BIDEGAIN (1996)

${ }^{28}$ Supóngase un caso en que la legislatura sanciona una ley tendiente al control de la matrícula de ciertos profesionales, para lo cual se requiere, entre otras cosas, la constitución de un consejo o colegio de profesionales que esté a cargo de ese control. Si, una vez sancionada la ley, el poder ejecutivo no convoca la conformación de ese colegio o no dispone ni los recursos ni los medios para que empiece a operar, aquella ley quedaría inoperante. Un buen ejemplo de cómo la no publicación de una ley constituye una herramienta del ejecutivo para impedir la entrada en vigencia de una ley que no es de su preferencia, puede encontrarse en MUSTAPIC (2000) y TSEBELIS y ALEMÁN (2007).

${ }^{29}$ Figura prevista en el Capítulo IV del Código Penal, arts. 248 y 249.

${ }^{30}$ Salvo Entre Ríos, que lo prevé en ocho días, y Santa Cruz, en dieciséis días.
} 
días) desde que el Poder Ejecutivo recepta el proyecto sancionado, el mismo se tiene por promulgado tácitamente (Tabla 1).

En cuanto a la reglamentación, el poder ejecutivo provincial tiene constitucionalmente asignada la potestad de reglamentar las leyes que sanciona el poder legislativo. Esta facultad es la que da nombre al poder ejecutivo, en cuanto órgano encargado de instrumentar y efectivizar las leyes. De acuerdo a la doctrina y jurisprudencia de la CSIN, los decretos reglamentarios constituyen derecho complementario de la ley, sus disposiciones integran la ley, tienen su misma fuerza imperativa y son decisivas para su interpretación ${ }^{31}$. Como se sostuvo anteriormente, la facultad de reglamentar leyes importa una tarea de índole legislativa a cargo del poder ejecutivo.

Todas las constituciones provinciales confieren esta facultad al gobernador ${ }^{32}$ pero, al mismo tiempo, limitan su ejercicio al principio de razonabilidad, en términos similares al contenido en el art. 28 y 99 , inc. $2^{\circ}$ de la Constitución Nacional ${ }^{33}$, que ponen un límite a la facultad reglamentaria, al disponer que el presidente "expide las instrucciones y reglamentos que sean necesarios para la ejecución de las leyes de la Nación, cuidando de no alterar su espíritu con excepciones reglamentarias" (ver tabla 1 en el anexo "Gráficos y Tablas").

\subsection{Decretos de necesidad y urgencia (DNU)}

Los DNU constituyen la facultad legisferante más importante en cabeza del ejecutivo y la más controvertida en el derecho local. Por un lado, encontramos que la gran mayoría de las constituciones provinciales contienen alguna cláusula genérica que prohíbe sea tanto la delegación de facultades legislativas a los poderes ejecutivos como la posibilidad de dictar decretos que, en sustancia, son verdaderas leyes.

Este poder ha sido denominado como "poder constitucional de decreto" y definido como "la facultad constitucional del Ejecutivo de expedir decretos de naturaleza legislativa sin que medie una delegación expresa de autoridad por parte de la legislatura (Carey y Shugart, 1998, p. 13)"34.

La doctrina jurídica, a partir del uso de este tipo de decretos, los ha denominado de necesidad y urgencia, dado que su uso ha sido justificado por causas donde, en principio, primaba la urgencia y necesidad de regular una determinada situación, que por su naturaleza urgente, hacía imposible esperar el prolongado tratamiento por parte de la Legislatura y el cumplimiento de todos los pasos y trámites establecidos para la sanción de leyes.

En el derecho público provincial encontramos así dos grandes grupos de constituciones según esté permitida esta facultad o no. 15 constituciones provinciales ${ }^{35}$ no contienen la posibilidad de que el ejecutivo pueda dictar este tipo de decretos y si a esta omisión se suma la existencia de una cláusula genérica que prohíbe la delegación legislativa en el ejecutivo, puede interpretarse que en este grupo de provincias, el poder ejecutivo tiene prohibido dictar decretos de necesidad y urgencia.

\footnotetext{
${ }^{31}$ SAGÜÉS (2003a) p. 597.

32 Buenos Aires (art. 144, inc. 2), CABA (Art. 102), Catamarca (art. 149, inc. 3), Chaco (art. 141), Chubut (Art. 155, inc. 1), Córdoba (Art. 144, inc. 2), Formosa (Art. 142, inc. 2), Jujuy (Art. 137, Inc. 4), La Pampa (Art. 81, inc. 3), La Rioja ( Art. $126^{\circ}$, inc. $1^{\circ}$ ), Mendoza (Art. 128, inc. 3), Neuquén (art. 116, inc. 2), Río Negro (Art. 181, inc. 5), Salta (Art. 144, inc. 3), San Juan (Art. 189, inc. 2), San Luis (Art. 168, inc. 1), Santa Cruz (Art. 119, inc. 2), Santa Fe (Art. 72, incs. 2 y 3), Santiago del Estero (Art. 157, inc. 1), Tierra del Fuego (Art. 135, inc. 3).

${ }^{33}$ CABA (Art. 102), Catamarca (arts. 3 y 29), Chaco (art. 141, inc. 3), Chubut (art. 155, inc. 1), Córdoba (Art. 144, inc. 2), Corrientes (Art. 162, inc. 2), Formosa (art. 142, inc. 3), Jujuy (Art. 137, Inc. 4.); La Pampa (Art. 81, inc. 3), Mendoza (Art. 128, inc. 3), Neuquén (art. 116, inc. 3), Río Negro (Art. 181, inc. 5), Salta (Art. 144, inc. 3), San Juan (Art. 189, inc. 2), San Luis (Art. 168, inc. 1), Santa Cruz (Art. 119, inc. 2), Santa Fe (Art. 72, incs. 2 y 3), Santiago del Estero (Art. 157, inc. 2), Tierra del Fuego (Art. 135, inc. 3), Tucumán (art. 101 , incs. 2 y 3 ).

${ }^{34}$ NEGRETTO (2002), p. 380 y NEGRETTO (2004) pp. 534-535.

${ }^{35}$ Buenos Aires, Catamarca, Córdoba, Corrientes, Ente Ríos, Formosa, Jujuy, La Pampa, Mendoza, Misiones, Neuquén, San Luis, Santa Cruz, Santa Fe y Tierra del Fuego. La actual gobernadora de la provincia de Catamarca envió a la Legislatura un proyecto de ley para modificar la Constitución provincial. Entre otros puntos, introduce la posibilidad de introducir los Decretos de Necesidad y Urgencia.
} 
Sin embargo, esta conclusión no resulta incontrastable, ya que la doctrina se encuentra dividida en este punto. Parte de ella sostiene que la no inclusión de este instituto no significa necesariamente una prohibición al ejecutivo de poder dictar este tipo de decretos. Su uso estaría justificado si concurriesen las circunstancias fácticas que lo habilitan -como sucedió en el orden federal.

Otra parte de la doctrina postula lo contrario. Bidart Campos sostiene que cuando una Constitución provincial no autoriza al Poder Ejecutivo a dictar estos decretos: "a) el principio prohibitivo surge de la división de poderes que, sin norma local expresa, ha de tenerse como regla impeditiva, $b$ ) el principio de autonomía significa que las provincias pueden prohibir los decretos referidos aunque la Constitución Federal los consienta a favor del presidente de la república; c) de la coordinación de los principios citados en los incisos a) y b) se desprende que transferir analógicamente al derecho provincial la permisión que en el orden federal habilita al Ejecutivo a dictar decretos de necesidad y urgencia es violar la autonomía provincial, porque en ejercicio de ellas las constituciones que no conceden similar permisión a los gobernadores deben interpretarse en el sentido de que la vedan" ${ }^{\prime 36}$. En última instancia, será el poder judicial de cada provincia el que debe decidir acerca de su validez, en caso de que, no estando previsto constitucionalmente, el ejecutivo emita decretos de este tipo.

Pese a su no inclusión en la constitución, en la práctica encontramos que los gobernadores han emitido decretos de esta naturaleza. En función de lo expuesto, cabe distinguir dentro de este grupo de provincias, aquellas donde el ejecutivo ha emitido decretos de necesidad y urgencia y, dentro de estas, a su vez, aquellas donde el poder judicial ha declarado la validez 0 invalidez de los mismos.

Así, del grupo de 15 provincias donde sus constituciones no habilitan esta posibilidad, en 9 de ellas, al menos, se han dictado normas de este tipo: Buenos Aires ${ }^{37}$, Córdoba ${ }^{38}$, Corrientes, Entre Ríos, Jujuy, Mendoza, Misiones, San Luis y Santa $\mathrm{Fe}^{39}$. De ellas, hemos encontrado jurisprudencia convalidatoria en tres casos: Entre Ríos ${ }^{40}$, Jujuy ${ }^{41}$ y Mendoza ${ }^{42}$. En solo un caso hemos encontrado jurisprudencia que rechaza la posibilidad de dictar DNU: Corrientes ${ }^{43}$.

\footnotetext{
${ }^{36}$ Citado por CHIACCHIERA y CALDERÓN (2013), p. 442.

${ }^{37}$ EI DNU N 40/07 que contiene políticas de seguridad vial (http://www.gob.gba.gov.ar/legislacion/legislacion/07-40.html); el DNU N. ${ }^{\circ} 2555$, de Septiembre de 2006, por medio del cual se autorizaba al Ministerio de Seguridad a ejercer las atribuciones previstas por la Ley 13.409, hasta tanto la Legislatura sancione el proyecto de ley que declare el estado de emergencia (el Poder Legislativo, al convalidar este DNU, mediante el art. 11 de la Ley 13.704, efectuó una suerte de delegación legislativa prohibida por el art. 45 de la Constitución provincial).

38 CALDERÓN y CHIACCHIERA (2013) enumeran 14 DNU dictados en la provincia, entre los años 2001 y 2003.

${ }^{39}$ En los casos de Formosa, La Pampa, Neuquén, Santa Cruz, Tierra del Fuego y de Tucumán no hemos podido conseguir datos sobre DNU dictados por los gobernadores.

${ }^{40}$ Superior Tribunal de Justicia de Entre Ríos, Fallo del 20/9/1997, “Bertoli, Aurelia T. y otro c/ Caja de Jubilaciones y Pensiones de la Provincia de Entre Rios", en LL, Litoral 1998-2:396.

${ }^{41}$ En la provincia de Jujuy existen varios precedentes del Tribunal Superior de Justicia de Jujuy donde se reafirman la facultad del gobernador de emitir decretos de necesidad y urgencia a pesar de no estar contenida esta facultad en el texto constitucional. En la causa "Centro de Docentes de enseñanza media y superior c/ Provincia de Jujuy", dictado por el Superior Tribunal de Jujuy, do nde diversos sindicatos de empleados públicos iniciaron acción de amparo solicitando la inconstitucionalidad del Decreto 3794-H-2001 por el que se fijaba el pago de sueldos mediante "tickets Canasta". En primera instancia se hizo lugar a lo solicitado, pero el gobierno provincial dedujo recurso de inconstitucionalidad contra dichas resoluciones y el TSJ finalmente rechazó las impugnaciones deducidas, convalidando la constitucionalidad del decreto. Otras causas, son "Arroyo de Heredia, María c/ Estado Provincial" Resolución del 05/05/1993; “Condori, Elba Margarita V Estado Provincial” Resolución del (15/04/1993); “Cardozo, Teresa Amalia v. Rivero, Juan Braulio y Estado Provincial", Resolución del 27/12/1994; "Morales, Gerardo Rubén y otro v. Estado Provincial”, Resolución del 14/3/1995; “Pasquine, Enrique Guillermo v. Estado Provincial”, Resolución del 27/12/1996; "Vazquez, Pedro Emilio v. Municipalidad de El Talar", Resolución del 13/10/1998, citados por CHIACCHIERA y CALDERÓN (2013), p. 443.

${ }^{42}$ En el caso de la provincia de Mendoza, hemos encontrado dos fallos que se refieren a la posibilidad del gobernador de dictar DNU. Uno de ellos, en la causa "Suchetti Guillermo c/ Empresa autotransportes los Andes S.A" (fallo del 03/03/2000, Fallo publicado en: L.L Gran Cuyo 2000, 345; Cita Online AR/JUR/3261/2000), el tribunal dispuso que el ejercicio de la facultad del poder ejecutivo de dictar DNU (en el caso, se discutía el Decreto № 260/97) exige que el mismo explique cuál es la situación crítica que impide esperar el trámite normal del congreso. Si bien en el caso concreto se declaró nulo el DNU, por no cumplir los recaudos que exige la jurisprudencia de la Corte Suprema de Justicia de la Nación para la validez de los mismos, el tribunal implícitamente reconoció tal facultad al gobernador. En el otro fallo donde se hace mención de los DNU, es "Cámara de comercio Industrial y Agropecuario de San Rafael c. Estado Nacional" (dictado el 8/3/2004, Publicado en: L.L GRAN CUYO 2004, cita online/JUR/618/2004), pero en este fallo el tribunal de primera instancia dio lugar a la medida cautelar solicitada suspendiendo los efectos del DNU.

${ }^{43}$ En una serie de fallos (Entre otros, fallos "Cardozo de Colombo, Amanda c/ Provincia de Corrientes" (del 15/4/1998), "Ledebur, Enrique L. c. Instituto de Prevision Social y/u otro" (del 21/9/1998), el Superior Tribunal de Justicia de la provincia sostuvo de modo
} 
En otras dos provincias encontramos jurisprudencia ambivalente al respecto. Así, en Buenos Aires la Suprema Corte de la provincia declaró primero la constitucionalidad de un DNU (decreto que había sido ratificado por ley de la legislatura provincial) ${ }^{44}$. Luego, declaró la inconstitucionalidad de otro DNU. Con posterioridad, hacia 2004, volvió a declarar la constitucionalidad de los DNU, volviéndolo a hacer en dos fallos ${ }^{45}$, aunque en estos casos también hubo ratificación de la Legislatura ${ }^{46}$. Por último, en un fallo del año 2011 declaró la inconstitucionalidad de los $\mathrm{DNU}^{47}$. Por lo que podemos observar, los pronunciamientos judiciales se inclinaron a favor de los DNU cuando estos habían sido ratificados por ley de la Legislatura.

En la provincia de Córdoba sucedió algo similar. Los distintos tribunales que consideraron la cuestión tuvieron opiniones (diametralmente) opuestas respecto de si el gobernador se encuentra o no habilitado para emitir decretos de necesidad y urgencia. Un grupo de fallos ${ }^{48}$, inclinándose por la tesis positiva, sostuvo que la omisión de esta facultad en el texto constitucional provincial "no importó la prohibición de hacerlo, sino que, por el contrario, el Constituyente se abstuvo de reglar el punto, quedando a criterio de los poderes constituidos la valoración en cada caso, de la constitucionalidad de los Decretos que en su mérito pudieran dictarse" 49 . En otro grupo de cuatro fallos ${ }^{50}$, se rechazó la posibilidad de que el gobernador pudiera emitir DNU, "al no existir norma alguna que permita su ejercicio" y, además, por la prohibición genérica del art. 13 de la constitución local que establece que "ningún magistrado o funcionario público puede delegar sus funciones en otra persona, ni un poder delegar en otro sus atribuciones constitucionales, salvo los casos previstos en esta Constitución, y es insanablemente nulo lo que cualquiera de ellos obrase en consecuencia" ${ }^{51}$. El caso cordobés resulta interesante desde que los DNU dejaron de ser utilizados luego de que se cambiara el formato de la legislatura, pasando de una bicameral a una unicameral y donde, además, el gobernador contaba con amplias mayorías legislativas provenientes de su propio partido del cual era el líder. La coincidencia de la variable partidaria (liderazgo partidario y gobierno unificado) hace pensar en la inutilidad del instituto para un gobernador que goza de mayorías en la legislatura.

En las provincias de Santa Fe y San Luis no se han encontrado aún datos sobre decisiones judiciales acerca de la validez o no de los DNU. En la provincia de San Luis, sin embargo, hemos encontrado decretos de necesidad y urgencia que fueron ratificados por la Legislatura local ${ }^{52}$. Finalmente, en la provincia de Misiones se registra un solo DNU, según un informe elaborado

categórico que los DNU carecen de todo sustento constitucional, y no resulta de aplicación las habilitaciones introducidas en la reforma de la Constitución Nacional de 1994, desde que las provincias tienen la facultad de darse sus propias instituciones de acuerdo al art. 121, CN (CHIACCHIERA Y CALDERÓN (2013), p. 442).

${ }^{44}$ Causa "Coronel, Oscar Adolfo y otros c/Municipalidad de Navarro s/Demanda contencioso administrativa" del 18/05/1999.

${ }^{45}$ Causa "Fiscal de Estado c/Provincia de Buenos Aires (Poder Ejecutivo) s/Demanda contencioso administrativa" del 18/02/2004 e "Iberargen S.A. c/Instituto Provincial de Lotería y Casino s/Amparo" del 01/12/2004.

${ }^{46}$ CHIACCHIERA y CALDERÓN (2013), p. 443.

${ }^{47}$ Causa "Rodríguez, Jorge Orlando c/ Fisco de la Provincia de Buenos Aires y otro/a s/ pretensión anulatoria - empl. Público" del $11 / 11 / 2011$.

${ }^{48}$ Causa "Cura, Norberto Julián y otro c/ Provincia de Córdoba" (Cámara Contencioso Administrativa de Segunda Nominación, Auto Nro. 40/2002) y "Toranzo, Juana V. c. Acevedo, Néstor R. y otra” (fallo de la Cámara de Apelaciones en lo Civil y Comercial de Sexta Nominación).

49 Considerando de la causa "Cura, Norberto", citado por CALDERÓN y CHIACCHIERA (2013).

50 "Bringas, Nicolás c/ Provincia de Córdoba" (resolución de la Cámara Contencioso Administrativa de Primera Nominación del 24/04/2002), "Córdoba, Carlos A. c/ Provincia de Córdoba" (de la Cámara de Apelaciones en lo Civil y Comercial de Primera Nominación del 08/03/2002), "Vexenat, Juan C. y otros c/ DIPAS" (resolución de la Cámara de Apelaciones en lo Civil y Comercial de Octava Nominación del 12/04/2002) y “Fernández, Raúl E. y otros c/ Provincia de Córdoba” (Auto Nro. 30/2002, del Tribunal Superior de Justicia de la provincia) (CALDERÓN y CHIACCHIERA (2013)).

${ }^{51}$ Del precedente del TSJ, “Fernández, Raúl” citado anteriormente. Lo curioso del precedente del máximo tribunal local, es que fue emitido en una conformación del mismo por conjueces, por una serie de recusaciones a los integrantes originales (CALDERÓN y CHIACCHIERA (2013)).

52 Decreto N² 2884 MGJyC 09 del 29/07/09 aprobado por las cámaras legislativas a través de la ley N V-0677-2009 sobre la restitución de tierras en propiedad al Pueblo Ranquel y decreto $\mathrm{N}^{\circ} 115-\mathrm{MHP}-11$ sobre un incremento salarial para los empleados públicos provinciales ratificado por ley XV-0757-2011. 
por la Comisión Especial Redactora del Digesto Jurídico de la Provincia de Misiones de mayo de $2009^{53}$ y sobre el cual no existe pronunciamiento judicial.

En el otro extremo encontramos un grupo de 9 provincias donde sus textos constitucionales autorizan la emisión de derechos de necesidad y urgencia: CABA, Chaco, Chubut, La Rioja, Río Negro, Salta, San Juan, Santiago del Estero y Tucumán. En estos casos, la inclusión en el texto constitucional se dio como consecuencia de la incorporación del instituto en la esfera nacional con la reforma de 1994, sumándose a Brasil, Chile (aunque solo para materia presupuestaria), Colombia y Perú en la esfera regional.

En este grupo de provincias encontramos, por lo general, cuatro disposiciones que regulan el instituto (ver Tabla 2): en primer lugar se establece, como principio general, la prohibición al poder ejecutivo de emitir disposiciones de carácter legislativo ${ }^{54}$; en segundo lugar, autorizan esta posibilidad solo cuando circunstancias excepcionales hicieran imposible seguir los trámites ordinarios previstos por la constitución para la sanción de las leyes ${ }^{55}$; en tercer lugar, se excluyen ciertas materias ${ }^{56}$. Por último, se establece como condición de validez de los DNU que los mismos sean ratificados por la legislatura.

Todas las constituciones establecen que el DNU deberá ser sometido a consideración de la Legislatura para su aprobación final. Si el poder ejecutivo no lo remite, el mismo queda automáticamente derogado. En cambio, si una vez remitido la Legislatura no se expide en un determinado tiempo establecido por la Constitución, el decreto queda convertido en ley. Así lo establecen expresamente Tucumán, San Juan, Salta, Río Negro y La Rioja. Las constituciones de CABA, Chaco y Santiago del Estero no establecen nada en caso de que la Legislatura local no emita dictamen sobre el instrumento. Chubut, en cambio, establece el principio contrario, disponiendo que "El decreto pierde efectos jurídicos si la Legislatura no lo ratifica con el voto de los tercios del total de sus miembros dentro del plazo de treinta días contados a partir de la fecha de su comunicación" (Art. 181, inc. 6). (Ver tabla 2 en el anexo "Gráficos y Tablas").

\subsection{Poder de veto}

El poder de veto se erige como un poder reactivo en manos del poder ejecutivo, en cuanto le permite frenar proyectos legislativos opuestos a sus preferencias, bloqueando la promulgación de una ley aprobada por el Congreso ${ }^{57}$. Permite así al ejecutivo obstaculizar el cambio ${ }^{58}$. Shugart y Mainwaring clasifican al veto en dos tipos: débil y fuerte. Consideran "veto débil" a aquel que puede ser superado por una insistencia parlamentaria que requiera una mayoría absoluta ( $50 \%$ más uno del total de los miembros) y "veto fuerte" a aquel que no tiene otro requisito más estricto ${ }^{59}$.

Sin embargo, nosotros introducimos una nueva variable para clasificar el veto en fuerte o débil, que es el formato de la legislatura. Por ello, resulta necesario diferenciar, en primer lugar, el formato de las legislaturas (si estas son unicamerales o bicamerales) y, en segundo lugar, las

\footnotetext{
53 Segundo informe de avance de la primera etapa del Digesto Jurídico de la Provincia de Misiones, disponible en http://www.diputadosmisiones.gov.ar.

${ }^{54}$ Esta prohibición genérica solo la prevén expresamente cuatro de las nueve constituciones: CABA (Art. 103), Chaco (Art. 142), Chubut (Art. 156), La Rioja (Art. 126, inc. 12), y Tucumán (Art. 101, inc. 2).

${ }^{55}$ Así lo disponen expresamente todas las constituciones del grupo: CABA (Art. 103), Chaco (Art. 142), Chubut (Art. 156), La Rioja (Art. Art. 126, inc. 12), Río Negro (Art. 181, inc. 6), Salta (Art. 145), San Juan (Art. 189, inc. 17), Santiago del Estero (Art. 158) y Tucumán (Art. 101, inc. 2, primera parte).

${ }^{56}$ La de San Juan establece que "no pueden ser materia de la legislación de necesidad y urgencia las decisiones legislativas, ni las leyes de base o programas legislativos, ni las atribuciones otorgadas por esta Constitución al Poder Legislativo en el artículo 150으, salvo en sus incisos 1, 3, 9, 12, 14 y 16 primera parte" sobre atribuciones del poder legislativo que establecen, respectivam ente, dictar las leyes que sean necesarias para hacer efectivos los derechos, deberes y garantías consagrados por la Constitución sin alterar su espíritu, establecer tributos, crear y suprimir empleos no previstos por la Constitución para la administración de la Provincia, declarar las causales de utilidad pública o de interés general para expropiaciones por leyes generales o especiales, y acordar subsidios a las municipalidades. En este sentido, San Juan presenta la habilitación constitucional a emitir DNU más restringida de este grupo de provincias.

${ }^{57}$ PAYNE (2006), p. 98.

${ }^{58}$ Kiewiet y McCubbins (1988), citados por MAINWARING y SHUGART (2002), p. 50.

${ }^{59}$ SHUGART Y MAINWARING (2002), p. 52.
} 
mayorías exigidas para que el poder legislativo pueda sobreponerse al veto del gobernador (insistencia parlamentaria). Así, por ejemplo, un gobernador que ha ejercido el veto debe luego someterlo a la consideración de una legislatura unicameral y si, al mismo tiempo, la constitución exige una mayoría absoluta de los presentes para que esta pueda insistir, su poder de veto no será de igual magnitud que la de un gobernador que debe someter su veto a la consideración de un poder legislativo compuesto por dos cámaras y que, al mismo tiempo, cada una de ellas deba superar una mayoría del total de los miembros, y no sobre los presentes.

En función de la incorporación de esta nueva variable, el veto se clasifica en cuatro clases: muy débil, débil, fuerte y muy fuerte. Así, un veto es muy fuerte cuando para insistir, una legislatura bicameral deba alcanzar 2/3 de los votos en ambas cámaras; el veto es fuerte cuando una legislatura bicameral necesite una mayoría absoluta de los miembros de cada cámara. EI veto será débil cuando se exija una mayoría de los $2 / 3$ de la cámara única, y muy débil si se requiere mayoría absoluta ${ }^{60}$ (ver gráfico 2 en el anexo "Gráficos y Tablas").

16 provincias cuentan con un formato de legislatura unicameral, lo que, en principio, facilitaría la insistencia parlamentaria, debilitando el poder de veto del gobernador. Asimismo, con respecto a las mayorías, dentro de este grupo encontramos una única provincia, Misiones, que exige una mayoría absoluta de los miembros de la legislatura para que esta pueda insistir en el proyecto original (aunque no se aclara si sobre el total o sobre los presentes). En este caso, como bien advierten Shugart y Mainwaring, "en última instancia no hay veto, sino una oportunidad para el [ejecutivo] de retrasar la promulgación y pedir una reconsideración, como sucede en Venezuela" 61.

Otras 11 provincias (Chaco, Chubut, Córdoba, Formosa, La Pampa, La Rioja, Neuquén, San Juan, Santa Cruz, Santiago del Estero, Tucumán) establecen que la mayoría necesaria para insistir es de dos tercios de los presentes. Y las cuatro restantes (CABA, Jujuy, Río Negro y Tierra del Fuego) establecen la misma mayoría de dos tercios, pero no especifican si es sobre el total o sobre los presentes ${ }^{62}$. Ninguna de estas provincias con legislaturas unicamerales establece expresamente una mayoría de los dos tercios sobre el total de los miembros del poder legislativo.

Por otro lado, del restante grupo de 8 provincias que cuentan con un formato de legislatura bicameral, 6 prevén una mayoría de los dos tercios de los miembros presentes de cada cámara (Buenos Aires, Entre Ríos, Mendoza, Salta, San Luis, Santa Fe). Las restantes dos (Catamarca y Corrientes) no especifican si los dos tercios son sobre el total o sobre los presentes. En todos los casos, sin embargo, se aclara que la mayoría de los dos tercios debe ser alcanzada por las dos cámaras que componen el poder legislativo (ver tabla 3 en el anexo "Gráficos y Tablas").

Como puede observarse en la Tabla 3, el grueso de las constituciones provinciales (23, el $95 \%$ ) exige una mayoría de 2/3:15 cuentan además con legislaturas unicamerales, y las restantes 8 con legislaturas bicamerales. Este último es el mismo procedimiento que se sigue en el nivel federal (art. 83, CN). Por tanto, desde el punto de vista de las mayorías necesarias para la insistencia, todas las constituciones cuentan con un poder de veto débil. Dentro de ellas, debemos considerar a 15 con un veto débil, desde que deben enfrentarse a un legislativo unicameral, y a 8 con un veto muy fuerte, en cuanto deben enfrentarse a un legislativo bicameral, y donde por tanto la mayoría debe ser alcanzada por dos cámaras, y no por una sola. Misiones constituye el único caso de veto muy débil.

Además de estas consideraciones generales, encontramos en las constituciones provinciales otro tipo de limitaciones especiales que restringen el poder de veto de los

\footnotetext{
${ }^{60}$ Estas clasificación se basa en los diseños institucionales existentes en el derecho público provincial argentino, dado que existen otros diseños institucionales que prevén otro tipo de requisitos, tales como una mayoría agravada de $3 / 5$ de los miembros del Congreso (PNUD 2004).

${ }^{61}$ SHUGART y MAINWARING (2002), p. 51.

62 Así, CABA establece los dos tercios "de sus miembros", Jujuy, "de los miembros de la Legislatura", Río Negro y Tierra del Fuego "de los votos".
} 
gobernadores. En principio, el poder ejecutivo podría utilizar su facultad de veto sobre cualquier tipo de ley (salvo en excepciones muy puntuales y expresas) y cuantas veces estime necesario. Sin embargo, en el derecho provincial comparado encontramos un grupo de seis constituciones que establecen un límite a la facultad de ejercer el veto. Así, se establece que si la legislatura vuelve a sancionar el mismo proyecto de ley en un período legislativo subsiguiente, el poder ejecutivo no podrá volver a usar su poder de veto y estará obligado a promulgarlo. En la Tabla 3 figuran estas provincias en cursiva y con subrayado, para diferenciarlas del resto, dado que su poder de veto no resulta ser, en última instancia, de igual magnitud. Las provincias de Buenos Aires (Art. 111), Corrientes (Art. 125), Salta (Art. 134) y San Luis (Arts. 137 y Art. 168, inc. 3, $2^{\circ}$ párr.) establecen que dicha prohibición subsistirá "en uno de los dos períodos legislativos subsiguientes", mientras que Catamarca (Art. 121) y Tucumán (Art. 75) lo fijan "en el período legislativo subsiguiente". En estos 6 casos, el poder de veto fuerte con que cuentan estos gobernadores se ve atenuado por una especial forma de insistencia parlamentaria. San Juan establece otro tipo de limitación. En su Constitución, se hace una clasificación de las leyes (art. 156), dividiéndolas en "Decisorias", "De base o programas legislativos", "Técnicas o reglamentarias" y "Medidas". La primera y la última no pueden ser vetadas por el poder ejecutivo ${ }^{63}$.

Un novedoso e interesante fallo, sin precedentes en el derecho público provincial y nacional ${ }^{64}$, declaró la inconstitucionalidad y dejó sin efecto el veto total promovido por el Jefe de Gobierno de CABA contra la ley de aborto no punible, la cual establecía el procedimiento para la atención integral en casos de abortos. El fallo - más allá de las consideraciones particulares del caso- realizó una consideración acerca de la especial naturaleza del instituto del veto (así como del dictado de los DNU, también autorizados por el Estatuto Organizativo de la ciudad ${ }^{65}$ y realizó un análisis acerca del uso excesivo de tales instrumentos ${ }^{66}$.

De acuerdo al tribunal, tal actitud implicaba, por un lado, "una flagrante violación a lo dispuesto en la primera parte del artículo 103 de la Constitución de la CABA, cuando prohíbe al Poder Ejecutivo, 'bajo pena de nulidad, emitir disposiciones de carácter legislativo'" y que, por otro lado - lo que es más llamativo aún - "a través del veto sistemático y repetido, ha impedido a la Legislatura definir la política legislativa en todo lo referente a la reglamentación de los derechos de los habitantes de la ciudad consagrados en la Constitución. Cuando el Jefe de Gobierno, en lugar de utilizar la facultad de veto en situaciones excepcionales que realmente justifiquen su empleo, la usa para decidir a su exclusivo arbitrio qué materias pueden ser tratadas por la Legislatura, y cuáles no, se está arrogando facultades propias del Poder

\footnotetext{
${ }^{63}$ Las Decisorias, son "aquellas que son dictadas como decisiones legislativas para generar diversas posiciones de gobierno dirigidas a la satisfacción del bien común. Las decisiones legislativas se adoptan según el trámite ordinario previsto para la sanción de las leyes, con los dos tercios de votos de los miembros presentes y no pueden ser vetadas por el Poder Ejecutivo" (art. 156, inc. 1ㅇ). Las medidas son "son aquellas dirigidas a resolver o disponer sobre situaciones no recurrentes de carácter administrativo, las cuales son aprobadas por el trámite abreviado en el seno de las comisiones internas de la Cámara" y si este tipo de leyes "implican un acto de control, no pueden ser objeto de veto por el Poder Ejecutivo" (Art. 156, inc. 4ㅇ).

${ }^{64}$ Fallo "Rachid, María de la Cruz y otros c/ GCBA sobre Amparo (art. 14 CCABA)", del Juzgado en lo Contencioso Administrativo y Tributario $\mathrm{N}^{\circ} 2$ de la CABA, sentencia del 05/07/2013. Este pronunciamiento representa un antecedente inédito en el derecho constitucional argentino, desde que "por primera vez en la historia judicial del país, un magistrado declara la inconstitucionalidad del veto a una ley" (Diario Página 12, "Una práctica que es "abusiva»", del 08/07/2013).

${ }^{65}$ En él se sostuvo que "son de carácter excepcional y extremo, en tanto suponen asumir un rol que no le es propio, y solo en razón de circunstancias extremas. Se trata de facultades excepcionales, que implican una interferencia del Poder Ejecutivo en funciones naturalmente atribuidas al Poder Legislativo, y que solo deberían ser utilizadas en casos de extrema gravedad, frente a situaciones que impliquen desconocimiento de los principios básicos del ordenamiento jurídico, o que dificulten o impidan la función administradora del Ejecutivo".

${ }^{66}$ Así se manifestó que "el uso desmesurado y excesivo de la facultad constitucional de veto, al igual que el de la emisión descontrolada de decretos de necesidad y urgencia, constituyen verdaderas formas de anulación del rol legislativo y consagran modalidades autoritarias de gobierno reñidas con el espíritu y la letra de nuestra constitución" y que, "más allá de su adecuación formal con las normas constitucionales, no respeta la exigencia de excepcionalidad, ya que su dictado se inscribe en el marco de un notorio abuso de la herramienta por parte del actual Jefe de Gobierno". Luego trajo a colación una serie de datos estadísticos acerca del uso del instrumento, manifestando que desde el inicio de la gestión (diciembre de 2007), el actual Jefe de Gobierno había vetado 115 leyes sancionadas por la Legislatura, es decir, un promedio de 21 leyes por cada año de mandato y más de 2 vetos por mes, si se tiene en cuenta la duración de los períodos legislativos, lo cual consideró "una tasa excesivamente alta si se considera, como ya se señaló, que se trata de una facultad excepcional, que debe ser ejercida con suma prudencia".
} 
Legislativo". Ante ello, se declaró la inconstitucionalidad del veto total, se tuvo por promulgada la ley y se ordenó su registro y publicación en el Boletín Oficial.

Este fallo, sin embargo, fue posteriormente dejado sin efecto por la Cámara de Apelaciones en lo Contencioso Administrativo y Tributario de la CABA (Resolución de fecha 29 de diciembre de 2015 en los mismos autos) bajo el argumento de la imposibilidad de revisión judicial del veto del Poder Ejecutivo en el caso concreto, sosteniendo que "el estudio judicial del veto del Poder Ejecutivo con fundamento en su irrazonabilidad resulta vedado para el Poder Judicial" (Cons. XV). Posteriormente, contra esta misma resolución del Tribunal de alzada, se plantearon recursos de inconstitucionalidad, que fueron parcialmente concedidos. Sin embargo, en el Dictamen $N^{\circ} 28$ (del 25/01/2017) emitido por la Fiscalía General Adjunta, en el punto que aquí interesa (IV.B, iv, páginas 14, 15 y 16), se concluye igualmente que la constitucionalidad del veto es un asunto que no es revisable en sede judicial: ...Este es un planteo que no resulta revisable aquí, no solo por los argumentos que diera la Corte Suprema en el fallo mencionado, sino también porque en este aspecto, la Constitución local le asigna a la Legislatura el rol preponderante, al marcar la necesidad de reenvío de la norma para que ella se allane a las objeciones o insista con mayoría calificada en el proyecto original (conforme artículo 87 in fine de la Constitución)" ${ }^{\prime \prime}$.

Por último, cabe analizar si las constituciones provinciales exigen al poder ejecutivo que este fundamente, o no, el ejercicio del veto sobre un proyecto de ley sancionado por la legislatura. El Estatuto Organizativo de CABA, establece que el ejecutivo podrá vetar una ley "expresando los fundamentos" (art. 87), la Constitución del Chaco en cuanto dispone que el gobernador "Veta total o parcialmente los proyectos de ley [...] dando los fundamentos en cada caso" (art. 141, inc. 4), la Constitución de San Luis (Art. 168, inc. 3, $2^{\circ}$ párr.) determina la facultad del ejecutivo de ejercer este instrumento, pero "expresando en detalle los fundamentos del veto", Misiones, "dando los fundamentos de las observaciones que formule" (Art. 116, inc. 3), Santiago del Estero, "expresando en detalle los fundamentos del veto" (Art. 157, inc. 2) y Tucumán, dispone también que debe ser "en forma fundada" (art. 71 y 72 , inc. $1^{\circ}$ ).

Por último, cabe aclarar que ninguna constitución provincial prevé un veto absoluto, es decir, cuando la Legislatura no cuenta con la facultad de insistir o resellar una ley aprobada por ella. En estos casos, el poder de veto se vuelve muy poderoso, "pues muy probablemente impedirá que el Poder Legislativo tome cualquier medida con la que el Ejecutivo disienta", como sucede en el caso de Ecuador (Payne 2006:98).

\subsection{Promulgación parcial}

A raíz de la posibilidad de vetar parcialmente un proyecto de ley, se desprende una nueva facultad del poder ejecutivo, cual es la de promulgar parcialmente un proyecto de ley sancionado por la legislatura, pero con algunas modificaciones o supresiones a su texto. Nótese que las facultades de vetar parcialmente una ley y la de promulgarla parcialmente son sustancialmente distintas, pudiendo ser válidamente ejercida una pero no la otra ${ }^{68}$.

En principio, y al menos en su concepción clásica, el veto parcial funciona de la siguiente manera: si el ejecutivo observa alguna parte de la ley, esta en su totalidad deberá ser enviada al legislativo, quien solo podrá reconsiderar la parte observada por el ejecutivo, pudiendo prestar su consentimiento a las observaciones y devolverlas para su promulgación y su publicación. Así lo consideraba el texto de la constitución nacional de 1853. Sin embargo, y a raíz de la práctica

\footnotetext{
${ }^{67}$ Se agradece la observación que sobre el punto ha hecho un evaluador anónimo.

${ }^{68}$ Se trata de "dos actos de naturaleza jurídica distinta. El primero, [veto parcial] impide la entrada en vigencia de una norma. En cambio, el segundo [promulgación parcial] completa el proceso formativo de las leyes determinando su entrada en vigencia, previa la publicación pertinente" (BADENI (1999), pp. 119 y 177 y ss.).
} 
de los presidentes de promulgar parcialmente proyectos de ley, en 1994 se introdujo explícitamente esta posibilidad ${ }^{69}$.

Todas las constituciones provinciales permiten la promulgación parcial, pero se observan al menos dos modalidades. Una de ellas - la modalidad más amplia- permite la publicación de cualquier tipo de ley y, por lo general, los textos constitucionales exigen que la parte no vetada mantenga "autonomía normativa" y no se vea afectada la "unidad y el sentido del proyecto" y otras exigen el consentimiento de la legislatura para que proceda la promulgación con las modificaciones del ejecutivo. La otra modalidad, en cambio, circunscribe esta facultad a un solo tipo de norma y, por lo general, se refiere al presupuesto general de gastos y recursos.

15 constituciones autorizan la promulgación parcial sobre cualquier tipo de ley ${ }^{70}$. De estas, Neuquén, San Luis, Santa Fe y Tucumán, prevén además expresamente la promulgación parcial de la ley general de presupuesto, conteniendo disposiciones idénticas al otro grupo de provincias cuyas constituciones autorizan exclusivamente la promulgación parcial respecto de la ley de presupuesto, como se verá más delante. Aquellas constituciones que autorizan la promulgación parcial sobre cualquier tipo de ley (15 en total) pueden contener asimismo dos prescripciones que limitan esta facultad: una de ellas es el requisito de que el proyecto, después de las supresiones o modificaciones del ejecutivo, mantenga "autonomía normativa" y "no altere el espíritu ni la unidad del proyecto sancionado por la Legislatura". El otro requisito se refiere a la conformidad de la legislatura, previa promulgación definitiva. En cuanto al primer requisito, lo establecen las constituciones de Chubut, Córdoba, Entre Ríos, Formosa, Salta, San Juan, San Luis, Santiago del Estero, Tierra del Fuego y Tucumán, utilizando términos más o menos similares a los expresados en el párrafo anterior. CABA, La Rioja, Neuquén, Santa Cruz y Santa Fe en cambio, no establecen los requisitos de unidad y autonomía normativa.

Asimismo, dentro de este grupo de 15 provincias, 8 establecen que el veto parcial deberá ser convalidado por la legislatura: CABA, Chubut, Córdoba, Neuquén, San Juan, Santa Fe, Santiago del Estero y Tierra del Fuego. De ellas, solo Chubut, Neuquén y Santa Fe establecen la mayoría necesaria para prestar ese consentimiento: Chubut la fija en $2 / 3$ de sus miembros, mientras que Neuquén y Santa Fe en una mayoría simple ${ }^{71}$.

En el otro grupo de las restantes 9 provincias, la promulgación parcial se circunscribe a la ley de presupuesto, o bien a la ley de presupuesto y aquellas que crean impuestos. Esta autorización circunscripta a la ley de presupuesto prevé que la ley observada será directamente publicada, no exigiéndose requisitos de unidad ni de consentimiento previo de la legislatura. A este grupo se agregan aquellas que prevén la promulgación parcial para cualquier tipo de ley y en especial de la de presupuesto, donde puede observarse más nítidamente la diferencia entre la promulgación parcial de cualquier ley y la que se refiere al presupuesto.

Así, seis constituciones, las de Buenos Aires (Art. 108), Catamarca (Art. 188), Chaco (Art. 118), Jujuy (Art. 121), Misiones (Art. 104) y Río Negro (Art. 146) autorizan la promulgación parcial con respecto a la ley de presupuesto. Otras tres, Corrientes (Art. 122), La Pampa (Art. 70) y

\footnotetext{
${ }^{69} \mathrm{El}$ art. 80 del texto constitucional nacional determina que "Los proyectos desechados parcialmente no podrán ser aprobados en la parte restante. Sin embargo, las partes no observadas solamente podrán ser promulgadas si tienen autonomía normativa y su aprobación parcial no altera el espíritu ni la unidad del proyecto sancionado por el Congreso". Aunque a continuación dispone que "En este caso será de aplicación el procedimiento previsto para los decretos de necesidad y urgencia".

${ }^{70}$ CABA (Art. 88); Chubut (Art. 142), Córdoba (Arts. 144 inc. 5, 109), Entre Ríos (Art. 129), Formosa (Art. 125), La Rioja (Art. 107), Salta (Art. 144), San Juan (Art. 169), Santa Cruz (Art. 107), Santiago del Estero (Art. 135), Tierra del Fuego (Art. 110), Neuquén (Art. 195), San Luis (Arts. 135 y 136), Santa Fe (Art. 59), Tucumán (Art. 71).

${ }^{71}$ Ninguna constitución provincial regula un procedimiento similar al previsto en la Constitución Nacional. Su art. 80, in fine, se refiere al caso de que el Ejecutivo decidiese promulgar parcialmente un proyecto de ley, y dispone que "en este caso será de aplicación el procedimiento previsto para los decretos de necesidad y urgencia". A su vez, el art. 99, inc. 3, último párrafo, detalla este procedimiento: "El jefe de gabinete de ministros personalmente y dentro de los diez días someterá la medida a consideración de la Comisión Bicameral Permanente, cuya composición deberá respetar la proporción de las representaciones políticas de cada Cámara. Esta comisión elevará su despacho en un plazo de diez días al plenario de cada Cámara para su expreso tratamiento, el que de inmediato considerarán las Cámaras. Una ley especial sancionada con la mayoría absoluta de la totalidad de los miembros de cada Cámara regulará el trámite y los alcances de la intervención del Congreso". Cabe aclarar que el dictamen de la Comisión Bicameral Permanente no es vinculante para las Cámaras del Congreso, puesto que estas son las depositarias de la facultad legislativa y las que deciden en definitiva sobre la validez o no de la promulgación parcial (BADENI (1999), p. 114).
} 
Mendoza (Art. 102), autorizan con respecto a la ley de presupuesto y además, de leyes impositivas (ver tabla 4 en el anexo "Gráficos y Tablas").

La posibilidad de poner en vigencia de forma automática un proyecto de ley aprobado por el legislativo, pero con algunas modificaciones hechas por el ejecutivo constituye "un poder de agenda condicional ${ }^{72}$; esto es, permite al presidente introducir una última propuesta que puede mitigar aquellas características no deseadas del proyecto de ley presentado por el Congreso, siempre y cuando pueda obtener el suficiente apoyo parlamentario para evitar su modificación o rechazo"73.

Este poder de agenda condicional se incrementa aún más si los textos constitucionales no exigen un consentimiento expreso por parte de las legislaturas (supuesto que Tsebelis y Alemán 2007 no tienen en cuenta), como sucede en 16 constituciones provinciales. En las restantes 8 constituciones se exige este consentimiento $y$, por lo tanto, atempera este poder de agenda pero, en cuatro de ellas no se dice qué tipo de mayoría es exigida para prestar el consentimiento. En cambio, en dos (Santa Fe y Neuquén) se establece expresamente una mayoría simple y Chubut es la única que prevé una mayoría agravada de dos tercios, convirtiendo en este caso al poder de agenda en uno muy débil.

\subsection{El poder exclusivo de iniciativa legislativa}

En la gran mayoría de los diseños constitucionales latinoamericanos, el presidente está expresamente facultado a introducir propuestas de cambio legislativo, a diferencia de lo que sucede en EEUU, donde solo el Congreso es el actor proactivo ${ }^{74}$. En el constitucionalismo subnacional argentino se ha seguido el mismo modelo que el federal, pero, además de esta facultad genérica de introducir proyectos de ley (iniciativa común), todas las constituciones provinciales han introducido el poder de iniciativa exclusiva sobre un determinado proyecto de ley.

De acuerdo a la clasificación de Shugart y Mainwaring (2002), el poder exclusivo de iniciativa legislativa constituye otra forma de poder reactivo, desde que los ejecutivos "pueden evitar todo cambio simplemente no introduciendo el proyecto de ley"75. Asimismo, encuentran que, en su análisis comparativo de las constituciones latinoamericanas, la mayoría de ellas otorga este poder en áreas muy sensibles, tales como la política militar, la creación de reparticiones burocráticas y el presupuesto. Se destacan las constituciones de Brasil, Chile y Colombia en cuanto otorgan importante facultades de iniciativa exclusiva a los presidentes ${ }^{76}$.

Todas las constituciones provinciales prevén el poder de iniciativa exclusiva. Con excepción de CABA y Jujuy, todas las restantes constituciones otorgan al gobernador la facultad de iniciativa exclusiva sobre la ley de presupuesto general de gastos y recursos. Ello no quita que el legislativo pueda introducir todas las modificaciones que estime necesario, pero las constituciones establecen que solo el gobernador puede presentar este proyecto. Sin embargo, al tratarse de una ley que necesariamente debe sancionarse todos los años, la facultad de iniciativa exclusiva en materia presupuestaria se torna débil, pues el gobernador está obligado a presentarla, y así no podría darse el supuesto que los autores mencionaban más arriba. A lo cual debe sumarse el hecho de que ninguna constitución prohíbe a las legislaturas introducir enmiendas a las leyes propuestas por el ejecutivo, o limitan de alguna manera la facultad de modificar el proyecto - como lo hacen las constituciones de Brasil, Colombia, Ecuador, El Salvador, Perú, Nicaragua, Panamá, Uruguay y Venezuela ${ }^{77}$.

\footnotetext{
72 TSEBELIS (1994).

73 TSEBELIS Y ALEMÁN (2007), p. 78.

${ }^{74}$ COLOMER Y NEGRETTO (2003).

${ }^{75}$ SHUGART y MAINWARING (2002), p. 57.

76 PAYNE (2006).

77 PAYNE (2006). La facultad de iniciativa exclusiva sobre el presupuesto difiere del orden federal, donde no está prevista como facultad exclusiva del presidente. El art. 100, inc. 6 faculta al Jefe de Gabinetes a "enviar al Congreso los proyectos de ley de ministerios y de presupuesto nacional, previo tratamiento en acuerdo de gabinete y aprobación del Poder Ejecutivo", pero no surge
} 
Además de la ley de presupuesto, las constituciones por lo general otorgan la iniciativa exclusiva en otro tipo de proyectos, tales como la ley de ministerios (10 provincias), de Plan Urbano Ambiental, en el caso de CABA o leyes sobre Impuestos, en La Pampa (ver tabla 5 en el anexo "Gráficos y Tablas").

\subsection{Pedido de urgente tratamiento}

Existe en el derecho público provincial un instrumento que permite al poder ejecutivo solicitar a la legislatura un tratamiento urgente de ciertos proyectos ${ }^{78}$.

Solo cuatro provincias prevén este instituto: Chaco (Art. 117), Chubut (Art. 144), San Luis (Art. 138) y Tierra del Fuego (Art. 111). El instituto es regulado en manera similar en los cuatro casos: el poder ejecutivo puede solicitar se imprima el trámite de urgente tratamiento a un determinado proyecto de ley, debiendo el mismo tratarse en un plazo perentorio de 60 días (Tierra del Fuego lo fija en 30 días) ${ }^{79}$. El pedido imprime esa calidad al tratamiento del proyecto, salvo que la legislatura decida rechazar el pedido de urgente. Para rechazarlo, la legislatura deberá alcanzar una determinada mayoría: así, Chaco establece "la mitad más uno de los miembros", Chubut la "mayoría de sus miembros" y San Luis "dos tercios de los miembros". Tierra del Fuego no especifica mayoría alguna.

Solo dos constituciones establecen límites a la facultad de imprimir el trámite de urgente a determinados proyectos de ley: Chaco establece que el procedimiento no será aplicable a los proyectos que se refieran a materia tributaria, electoral o del presupuesto general, a la reglamentación de derechos y garantías constitucionales y a reformas de la Constitución y, además, que no podrán tramitarse en la Legislatura más de tres proyectos con dicha calificación, simultáneamente. San Luis lo prohíbe respecto del proyecto de Ley de Presupuesto.

Chubut y Tierra del Fuego, en cambio, establecen respecto del presupuesto, el principio contrario: ambas disponen que la Legislatura puede dejar sin efecto el trámite de urgencia a los proyectos presentados por el ejecutivo, pero no con respecto del Proyecto de Ley de Presupuesto.

Por último, el trámite de urgente tratamiento da la ventaja al poder ejecutivo de que si transcurrido el plazo de 60 días previstos y no sean expresamente rechazados por la Legislatura, se tienen por aprobados. Las cuatro constituciones prevén esta solución. Este procedimiento incrementa el poder de agenda del ejecutivo e invierte los papeles en comparación con el procedimiento legislativo ordinario sometido al veto del ejecutivo ${ }^{80}$. En Latinoamérica, Uruguay y Ecuador receptan este poder (ver tabla 6 en el anexo "Gráficos y Tablas").

\section{Midiendo el grado de los poderes de legislación}

La Tabla 7 muestra un índice de los poderes constitucionales de legislación con que cuentan los gobernadores de provincia en Argentina, en función de una serie de indicadores elaborados de acuerdo a los distintos diseños institucionales observados en el constitucionalismo subnacional argentino, y sobre la base del índice propuesto por el PNUD ${ }^{81}$. La Tabla no contempla todas las situaciones que hemos descripto en el derecho público provincial y que de hecho se dan en la práctica cotidiana (tales como el dictado de DNU sin estar expresamente prevista esta facultad en la Constitución respectiva), pero aun así, constituye una valiosa herramienta para estandarizar criterios de clasificación, permitiendo comprar no solo a las provincias entre sí, sino también con el nivel federal y con el resto de los países de

\footnotetext{
del texto que esta sea una iniciativa exclusiva del poder ejecutivo. En este sentido, el sistema argentino es similar al Congreso, en el sentido de que cualquier legislador puede presentar un proyecto de ley de presupuesto alternativo.

${ }^{78}$ Esta facultad está prevista en las constituciones de Uruguay, Ecuador y Brasil (PAYNE (2006), p. 102).

79 San Luis prevé además el procedimiento de "muy urgente tratamiento", en cuyo caso las cámaras cuentan con 30 días (15 cada una) para tratar el proyecto.

${ }^{80}$ COLOMER y NEGRETTO (2003), p. 37.

81 PNUD (2004), pp. 76-77, Tabla 43.
} 
Latinoamérica ${ }^{82}$. La Tabla se complementa de todas maneras con el Anexo $\mathrm{N}^{\circ} 1$, en cuanto proporciona información más detallada (ver tabla 7 en el anexo "Gráficos y Tablas").

Una primera conclusión que puede extraerse de la Tabla 7 es que los gobernadores de provincia poseen tantos (e incluso más fuertes) poderes de legislación que el propio presidente de la República. Las provincias arrojan un promedio de 2,97, mientras que el presidente de 3,03. Sin embargo, 13 gobernadores provinciales (el 54\%) superan ampliamente al nivel federal, que van desde 4,23 (Salta y San Luis) hasta 3,06 (Río Negro).

En particular, puede observarse que el poder de los ejecutivos provinciales (al igual que en el nivel federal) radica en el poder de veto fuerte y en la posibilidad (constitucionalmente reconocida) de emitir DNU. Así, las nueve provincias que tienen la facultad constitucional de emitir DNU, junto con el nivel federal, se posicionan sobre el resto.

Del análisis comparado de las constituciones provinciales se ha podido constatar que el diseño institucional dota a los poderes ejecutivos provinciales de importantes poderes tanto proactivos como reactivos. En cuanto a los poderes proactivos sobresale la facultad del ejecutivo de dictar DNU. Bien esté previsto o no por los textos constitucionales, la mayoría de los gobernadores cuentan con esta herramienta: 17 de 24 gobernadores (el 68\%) han emitido un DNU, sobreponiéndose de esta manera a las facultades del poder legislativo ${ }^{83}$. De aquellos 17 , nueve (el 52\%) cuentan con habilitación constitucional expresa, lo que incrementa este poder, dado que no correrían el riesgo de ser declarados inconstitucionales, como le sucedió a los gobernadores de las provincias de Buenos Aires, Córdoba y Corrientes. A su vez, de estos nueve casos, solo la provincia del Chubut establece que frente al silencio de la Legislatura, el DNU perderá sus efectos jurídicos. La Rioja, Río Negro, Salta, San Juan y Tucumán expresamente prevén que si la Legislatura, en un determinado plazo, no se decide por la validez del decreto, el mismo queda convertido en ley, lo cual incrementa sustancialmente este poder proactivo. Algo similar sucedió en el nivel federal, tanto antes de su incorporación al texto constitucional en 1994 (por convalidación jurisprudencial), como después de incorporado al texto, frente a la no constitución de la Comisión Bicameral permanente que prevé la Constitución.

De los ocho gobernadores restantes - que no cuentan con habilitación constitucional expresa, pero de todas maneras han sancionado un DNU - encontramos que en la mayoría de los casos los poderes judiciales han convalidado esta facultad implícita: en seis casos los tribunales locales han aceptado la facultad invariablemente, en dos casos (Buenos Aires y Córdoba) la jurisprudencia se ha mostrado ambivalente, aprobando en algunos casos y rechazando en otros y en un único caso el superior tribunal local se inclinó decididamente por el rechazo (Corrientes).

La Tabla 7 tiene en consideración únicamente a aquellas provincias con habilitación especial, clasificando los distintos tipos de DNU y sus procedimientos en una escala de 0 (sin facultad de emitir DNU) a 5 (donde la habilitación no excluye materias y el silencio de la legislatura convierte el decreto en ley). En este ranking, todas las constituciones provinciales son superiores al federal $(0,40)$, excepto Chubut $(0,20)$.

Dentro de los restantes poderes proactivos, encontramos las facultades de iniciativa exclusiva y el pedido de urgente tratamiento. Todas las constituciones provinciales otorgan al gobernador la exclusividad sobre determinadas materias, en particular una de las más sensibles, que es el presupuesto general de gastos y recursos. A pesar de que las legislaturas no se ven impedidas de implementar las modificaciones que estimen necesarias, al ser el gobernador el único habilitado para presentar el proyecto, este tiene así de antemano las pautas generales del mismo, pudiendo establecer al menos las bases para el debate inicial. A ello cabe agregar que todas las constituciones habilitan al gobernador a publicar el presupuesto en las partes no vetadas, difiriendo el tratamiento de los puntos observados por el gobernador. En materia de

82 El análisis comparativo a nivel latinoamericano requeriría, sin embargo, una cierta adecuación de los distintos diseños institucionales en una clasificación más amplia, pero al mismo tiempo parsimoniosa de la gran diversidad de diseños institucionales existentes, dado que difieren mucho aquellos del nivel subnacional argentino con los nacionales latinoamericanos.

${ }^{83}$ De los restantes siete, sin embargo, no disponemos actualmente de datos acerca de si se han emitido o no DNU. 
iniciativa exclusiva, sobresalen con el máximo puntaje las provincias de Chaco y Chubut $(1,00$ cada una), pues estas provincias no solo tienen iniciativa en materia de presupuesto, sino que además pueden imprimirle el trámite de urgente tratamiento.

En cuanto a los trámites de urgente tratamiento, solo cuatro provincias prevén este instituto (Chaco, Chubut, San Luis y Tierra del Fuego). En estos casos, el poder proactivo de los gobernadores se incrementa bastante, debiendo sumar a ello el hecho de que estas constituciones prevén que transcurrido un determinado plazo (60 días) sin que la legislatura se haya expedido sobre los proyectos, se tendrán por aprobados. Las cuatro provincias que cuentan con esta facultad incrementan su posición dentro del ranking de la Tabla 7, posicionándolas entre los primeros lugares.

Estos últimos dos poderes reactivos son una innovación del derecho provincial respecto del federal, ya que el presidente no cuenta con ninguno de ellos.

Dentro de los poderes reactivos, el veto se erige como el más importante. En el ranking de la Tabla 7, las provincias arrojan un promedio de 0,87 , en una escala de 0 a 6 puntos. Seis provincias junto con el orden federal alcanzan la máxima puntuación $(6=1,00)$.

Así, encontramos que 15 gobernadores (el 63\%) cuentan con un veto débil y uno solo (4\%) con un veto muy débil. Los restantes ocho gobernadores (el 33\%) cuentan con un poder de veto muy fuerte. Sin embargo, dentro de esta minoría del 33\%, encontramos además que 5 tienen una especial forma de insistencia parlamentaria contenida en sus textos constitucionales: si la legislatura vuelve a sancionar el mismo proyecto de ley en uno o dos períodos legislativos subsiguientes, el ejecutivo no podrá volver a usar su poder de veto y estará obligado a promulgarlo. Lo cual significa que en estos casos su poder de veto se traduciría en una suspensión de la ley por el término de uno o dos años. Dentro del grupo de gobernadores con poder de veto débil, solo Tucumán prevé esta forma especial de insistencia parlamentaria, lo que debilita aún más el veto. Por su parte, San Juan prevé además que cierto tipo de legislación no puede estar sujeta al veto del gobernador. En este sentido, el orden federal prevé un tipo de veto muy fuerte, sin ningún tipo de limitaciones como las que se observan en el orden provincial.

Otro de los poderes reactivos en manos del gobernador es la posibilidad de promulgación parcial sobre determinados proyectos aprobados por la legislatura. Respecto de este poder, hemos encontrado dos categorías en las constituciones provinciales: una de ellas que autoriza la promulgación parcial sobre cualquier tipo de ley, mientras que la otra lo autoriza solo respecto de determinados proyectos de ley, por lo general circunscripto al presupuesto. En el ranking de la Tabla 7, las provincias muestran un promedio de 0,52 , mientras el presidente una puntuación de 0,63 . Sin embargo, ocho provincias superan al nivel federal (con $1,00,0,88$ y 0,75 ) y otras cuatro lo igualan. Así, 15 constituciones (el 63\%) autorizan la promulgación parcial sobre cualquier tipo de ley, mientras que las 8 restantes (el $38 \%$ ) la autorizan solo respecto de la ley de presupuesto. Dentro de estas, en 3 casos se autoriza además respecto de leyes sobre impuestos (Corrientes, La Pampa y Mendoza). Dentro del grupo de las primeras 15 constituciones, 8 de ellas exigen el consentimiento previo de la legislatura, para que el proyecto pueda ser publicado con las enmiendas y observaciones del ejecutivo, lo cual debilita este poder reactivo en manos del gobernador.

Por otro lado, hemos visto que la facultad de publicación de una ley queda en manos del ejecutivo y esta se constituye en una herramienta que le permite diferir en el tiempo la entrada en vigencia de una ley que no es de su preferencia, o bien directamente impedirla, simplemente no publicando la ley -0 no reglamentándola. Solo 10 constituciones (el 42\%) prevén expresamente la posibilidad de que la legislatura ordene la publicación del texto aprobado en caso de que el gobernador no lo hiciere, coartando aquella posibilidad de diferir o impedir la entrada en vigencia de una ley. 12 provincias (50\%) se encuentran en igual situación que el presidente de la nación: cuentan con la facultad de publicar, pero sin plazo y la Legislatura no tiene facultad de hacer publicar la ley. 


\section{Conclusiones. El poder de agenda de los ejecutivos subnacionales}

En el presente trabajo se han analizado los poderes constitucionales sobre la legislación en manos del poder ejecutivo, de acuerdo al diseño institucional adoptado por las distintas constituciones provinciales. Esta constituye una primera aproximación en orden a determinar el verdadero papel que juegan los ejecutivos provinciales dentro de los sistemas políticos provinciales respectivos. Con ello se pretende además dejar líneas de investigación abiertas para profundizar esta temática, tales como el análisis del diseño institucional de las legislaturas, así como sus conformaciones efectivas, el sistema de partidos políticos y los sistemas electorales implementados, a los efectos de determinar los denominados poderes partidarios de los gobernadores. Ello permitirá analizar la conformación de los poderes ejecutivos y legislativos en las provincias para determinar el verdadero peso que tienen los gobernadores en la arena política local.

Amén de este objetivo (más amplio y ambicioso), el presente trabajo busca poner de resalto la importancia del diseño institucional y la estructura constitucional de los poderes ejecutivos en un tema muy sensible dentro de los sistemas presidencialistas: las facultades de legislación con que cuentan los ejecutivos, con independencia de otras variables (tales como los poderes partidarios). Y es precisamente en este objetivo que el trabajo se aparta de Mainwaring y Shugart (2002), buscando al mismo tiempo presentar una clasificación superadora de la propuesta por los autores. En la clasificación de Mainwaring y Shugart los poderes ejecutivos pueden ser fuertes o débiles según los poderes legislativos y poderes partidarios con que cuenten; es la combinación de ambas variables la que permite determinar la fortaleza o debilidad de un presidente ya que, en conjunción, le permitirán a este implementar sus políticas deseadas (o evitar las indeseadas). Sin embargo, de la propuesta de Mainwaring y Shugart se desprende que es el poder partidario la variable que define en última instancia la fortaleza del ejecutivo. Los autores clasifican a los presidentes según la constelación de poderes presidenciales sobre la legislación en las constituciones en presidentes potencialmente dominantes y presidentes potencialmente marginales ${ }^{84}$. Los primeros son aquellos que cuentan con importantes poderes de legislación (decreto, veto fuerte, introducción exclusiva), los segundos en cambio son aquellos que no tienen poderes de legislación. Pero los autores recurren al término "potencialmente" porque en definitiva lo relevante en la clasificación son los poderes partidarios: un presidente con importantes atribuciones legislativas pero con escaso apoyo partidario en el Congreso (sea porque no tiene mayoría o por indisciplina partidaria) será un presidente débil. En cambio, un presidente que no cuenta con importantes poderes de legislación pero sí con un importante contingente legislativo del partido que lidera, será un presidente fuerte ${ }^{85}$. En definitiva, los poderes de legislación pierden relevancia frente a los poderes partidarios ${ }^{86}$.

Lo que este trabajo intenta resaltar - sin desconocer la importancia que los poderes partidarios y las mayorías legislativas tienen en los sistemas presidenciales - es la capacidad de los ejecutivos de contar con mecanismos para introducir sus temas en la agenda legislativa, mecanismos que son definidos por la estructura institucional/constitucional con independencia de los poderes partidarios. Así entonces el factor que incide sobre la fortaleza o debilidad del ejecutivo desde el punto de vista de los poderes de legislación no pasa tanto por las mayorías legislativas en sí, según el esquema de Shugart y Mainwaring (2002), sino por el hecho de si es necesario o no la intervención del poder legislativo a la hora de fijar un tema en la agenda. Si se requiere su intervención, el poder de agenda del ejecutivo será débil, como sucede cuando los

\footnotetext{
84 SHUGART y MAINWARING (2002), p. 59.

85 "Si los presidentes colombianos hubieran podido apoyarse en mayorías disciplinadas, podrían haber convertido su predominio potencial en predominio real" (SHUGART y MAINWARING (2002), p. 61).

${ }^{86}$ Esta idea queda reforzada en MAINWARING y SHUGART (2002). En efecto, cuando un presidente cuenta con importantes mayorías parlamentarias, los "frenos y contrapesos son neutralizados en forma considerable" (p. 257), e incluso la independencia entre poderes (principal característica de los sistemas presidencialistas) queda desdibujada.
} 
DNU deben ser aprobados por la legislatura, perdiendo vigencia en caso contrario. Si el ejecutivo en cambio no necesita del consenso de la legislatura para un determinado asunto, su poder de agenda será mayor. Así por ejemplo, el poder de agenda unilateral por excelencia es la facultad de imprimir trámite de urgente tratamiento a un proyecto de ley. De ahí que en el índice de la Tabla 7 las cuatro constituciones provinciales que prevén este instituto se posicionan entre los primeros lugares del ranking, precisamente porque otorgan a sus ejecutivos una fuerte herramienta para fijar un tema de su interés en la agenda parlamentaria de manera unilateral.

Estos aportes originales buscan también contribuir a la literatura del derecho comparativo y del análisis de sistemas políticos comparados, desde que el marco teórico propuesto no queda limitado a la esfera subnacional argentina, sino que son plenamente aplicables (con correcciones y ajustes que cada sistema en particular requiere) a cualquier sistema jurídico.

\section{BiBLIOGRAFÍA CITADA}

AlBeRDI, JUAN BAUtISTA (1994): Bases y Puntos de Partida para la Organización Política de la República Argentina (Buenos Aires, Plus Ultra).

Almaraz, María Gabriela (2010): “Ambición política por la reelección en las provincias argentinas", en: Revista SAAP (Vol. 4, № 2, nov.), pp. 191-226.

AltaVILLA, CRIStian (2016): Conflicto y Coordinación política en las Relaciones Intergubernamentales en Argentina. Un análisis neoinstitucional a través del Régimen de Coparticipación Federal de Impuestos, Tesis Doctoral (Argentina, Universidad Nacional de Córdoba).

(2017): "La reelección en el Derecho Público Provincial", en: Revista de la Facultad (Vol. VIII, № 1, Nueva serie II), pp. 123-150.

BADENI, GREGORIO (1999): "Efectos del veto y la promulgación parcial de las leyes", en: Anales de la Academia Nacional de Ciencias Morales y Políticas, Buenos Aires (Tomo 28), pp. 109-120.

BENTON, ALLYSON LUCINDA (2003): “Presidentes fuertes, provincias poderosas: la economía política de la construcción de partidos en el sistema federal argentino", en: Política y Gobierno (Vol. X, № $1,1^{\text {er }}$ Sem.), pp. 103-137.

BidART CAMPOS, Germán (1997): Manual de la Constitución Reformada (Buenos Aires, Ediar), tomo III.

Bidegain, CARlos María (1996): Curso de Derecho Constitucional (Buenos Aires, Abeledo-Perrot), tomos III y IV.

BonVECCHI, ALEJANDRO Y LodolA, GERMÁN (2011): "The Dual Logic of Intergovernmental Transfers: Presidents, Governors, and the Politics of Coalition-Building in Argentina", en: Publius: The Journal of Federalism (Vol. 41, № 2, Spring), pp. 179-206.

Caedarello, ANTONIo (2012): "El irresistible anhelo de inmortalidad. Los gobernadores y la reelección inmediata en Argentina (1983-2007)", en: Revista SAAP (Vol. 6, № 1, mayo), pp. 153194.

Calderón, Maximiliano y Chiacchiera Castro, Paulina (2013): "Los decretos de necesidad y urgencia en la Provincia de Córdoba", en: APC 2013-5-547.

Calvo, ERnesto y Micozzi, Juan Pablo (2005): “The Governor's Backyard: A Bayesian Model to Estimate Partisan Bias in Multiparty (Subnational) Electoral Reforms", en: Journal of Politics (Vol. 67, № 4), pp. 1050-1074.

Calvo, Ernesto y Escolar, Marcelo (2005): La Nueva Política de Partidos en Argentina: crisis política, realineamientos partidarios y reforma electoral (Buenos Aires, Prometeo). 
Chiacchiera Castro, Paulina y Calderón, Maximiliano (2013): "Los decretos de necesidad y urgencia en las provincias", en: Alonso Regueira, Enrique M. (Dir.), Estudios de Derecho Público, Revista de la Asociación de Docentes, Facultad de Derecho y Ciencias Sociales (Buenos Aires, Universidad de Buenos Aires), pp. 433-447.

Colomer, Josep y Negretto, Gabriel (2003): "Gobernanza con poderes divididos en América Latina", en: Política y Gobierno (Vol. X, № 1, I Semestre), pp. 13-61.

Escolar, Marcelo (2011): “Nacionalización, comunidad cívica y coordinación electoral. Problemas para la integración del sistema político en estados democráticos multinivel", en: Revista SAAP (Vol. 5, № 2, nov.), pp. 263-304.

Gargarella, Roberto (2014): La sala de máquinas de la Constitución. Dos siglos de constitucionalismo en América Latina (1810-2010) (Buenos Aires, Katz Editores).

Gervasoni, CARlos (2010A): "A Rentier Theory of Subnational Regimes Fiscal Federalism, Democracy, and Authoritarianism in the Argentine Provinces", en: World Politics (Vol. 62, № 2, April), pp. 302-340.

(2010B): "Measuring Variance in Subnational Regimes: Results from an ExpertBased Operationalization of Democracy in the Argentine Provinces" en: Journal of Politics in Latin America (Vol. 2, № 2), pp. 13-52.

(2011): "Democracia, autoritarismo e hibridez en las provincias argentinas: la medición y causas de los regímenes subnacionales", en: Journal of Democracy en Español (Vol. 3), pp. 75-93.

GIRAUDY, AGUSTINA (2011): "La política territorial de la democracia subnacional", en: Journal of Democracy en Español (Vol 3), pp. 42-57.

GoRdillo, Agustín (2013): Tratado de derecho administrativo y obras selectas, Parte general (Buenos Aires, F.D.A.), tomo 1.

HOWELL, WILLIAM G. (2006): "Executives - The American Presidency", en: Rhodes, R.A.W; Binder, Sarah A. y Rockman, Bert A. (Eds.), The Oxford Handbook of Political Institutions (Oxford, Oxford University Press), pp. 303-322.

JONES, MARK (1998): "Explaining the high level of party discipline in the Argentine Congress" en: Documento de Trabajo $\mathrm{N}^{\circ}$ 14, CEDI - Universidad de San Andrés, Julio. Disponible en: http://repositorio.udesa.edu.ar/jspui/handle/10908/341 [visitado el 10 de junio de 2019].

(2002): “Una evolución de la democracia presidencialista argentina: 1983-1995” en: Mainwaring, Scott y Shugart, Matthew (Comp.), Presidencialismo y Democracia en América Latina (Buenos Aires, Paidós), pp. 213-253.

Jones, MARK Y HWANG, Wonjae (2005): “Provincial Party Bosses: Keystone of the Argentine Congress", en: Levitsky, Steven y Murillo, María Victoria (Eds.), Argentine Democracy: The Politics of Institutional Weakness (University Park PA, The Pennsylvania State University Press), pp. 115-38.

Jones, Mark; SAnguinetti, Pablo y Tommasi, Mariano (1997B): "Politics, Institutions, and Public Sector Spending in the Argentine Provinces", en: Documento de Trabajo $\mathrm{N}^{\circ} 17$, Universidad de San Andrés, Agosto. Disponible en: http://repositorio.udesa.edu.ar/jspui/handle/10908/341 [visitado el 10 de junio de 2019].

(2000): "Politics, institutions, and fiscal performance in a federal system: an analysis of the Argentine provinces", en: Journal of Development Economics (Vol. 61), pp. 305-333. 
LANDON, STUART (2003): "Sub-National Government Borrowing in Federal Systems: Evidence from Argentina and Mexico", en: Boothe, P. (Ed.), Fiscal Relations in Federal Countries: Four Essays (Ottawa, The Forum of Federations), pp. 53-68.

LEIRAS, MARCELo (2010): “Los procesos de descentralización y la nacionalización de los sistemas de partidos en América Latina”, en: Política y Gobierno (Vol. XVII, № 2, 2ㅇ Semestre), pp. 205241.

MainWARING, SCOtT y SHUgaRT, MATTHeW Soberg (2002): "Presidencialismo y democracia en América Latina: una revisión de los términos del debate", en: Mainwaring, Scott y Shugart, Matthew (Comps.), Presidencialismo y Democracia en América Latina (Buenos Aires, Paidós), pp. 19-64.

MUSTAPIC, ANA MARIA (2000): “'Oficialistas y diputados': las relaciones Ejecutivo-Legislativo en la Argentina", en: Desarrollo Económico (Vol. 39, № 156, Jan. - Mar), pp. 571-595.

Negretto, Gabriel (2002): “¿Gobierna solo el Presidente? Poderes de decreto y diseño institucional en Brasil y Argentina”, en: Desarrollo Económico (Vol. 42, № 167), pp. 377-404.

(2003): "Diseño constitucional y separación de poderes en América Latina", en: Revista Mexicana de Sociología (Vol. 65, № 1), pp. 41-76.

(2004): "Government Capacities and Policy Making by Decree in Latin America: The Cases of Brazil and Argentina", en: Comparative Political Studies (Vol. 37), pp. 531-562.

(2013): Making Constitutions. Presidents, Parties and Institutional Choice in Latin America (Cambridge, Cambridge University Press).

OLMEDA, JUAN CRUz (2009): "Relaciones intergubernamentales y patrones de negociación en el federalismo fiscal argentino desde los noventa", en: XXVIII Congreso Internacional de la Asociación de Estudios Latinoamericanos (LASA), Río de Janeiro, 11 al 14 de junio. Disponible en: https://hispanismo.cervantes.es/asociaciones/latin-american-studies-association-lasa [visitado el 10 de junio de 2019].

Olmeda, Juan Cruz y SuÁrez CaO, Julieta (2007): "The Federal Connection: Organizational Strategies and the Development of Conservative Parties in Mexico and Argentina", en: Midwest Political Science Association Annual Conference (Chicago).

PASQUINO, GIANFRANCO (2010): Sistemi politici comparati (Bologna, Bologna University Press).

PAYNE, J. MARK (2006): "El equilibrio de poder entre el Ejecutivo y el Legislativo: papel de la Constitución y los partidos políticos" en: Payne, J. Mark: Zovatto, Daniel y Mateo Díaz, Mercedes (2006): La política importa. Democracia y desarrollo en América Latina (Washington, D.C., Banco Interamericano de Desarrollo / Instituto Internacional para la Democracia y la Asistencia Electoral), pp. 91-128.

PNUD (PRograma de LAS NACIONES UnIDAS PARA el DeSARRolLo) (2004): La democracia en América Latina: hacia una democracia de ciudadanas y ciudadanos. Compendio estadístico (Nueva York, PNUD).

SAGüÉs, NÉstor Pedro (2003A): Elementos de Derecho Constitucional (Buenos Aires, Astrea), tomo I.

(2003в): Elementos de Derecho Constitucional (Buenos Aires, Astrea), tomo II.

SAIEgH, SEBAStiÁN (2010): “¿Jugadores activos o apéndices del ejecutivo? Una evaluación del papel de los legisladores latinoamericanos en la toma de Decisiones", en: Política y Gobierno (Vol. XVII, № 1, 1은 Semestre), pp. 3-24. 
SAIEGH, SebAStiÁN Y MARIANO TOMMASI (1998): "Las Instituciones Fiscales Federales en la Argentina: Estudio de caso dentro de la teoría del costo de las transacciones en la política", en: PNUD, Conferencia sobre Modernización y Desarrollo Internacional en la Argentina 20 y 21 de mayo (Buenos Aires, PNUD).

(1999): "Why is Argentina's Fiscal Federalism so Inefficient? Entering the Labyrinth", en: Journal of Applied Economics (Vol. II), pp. 169-209.

SAWERS, LARRY (1996): The Other Argentina. The Interior and National Development (Boulder, Westview Press).

SHUGART, MATTHEW SOBERg Y MAINWARING, SCOTT (2002): "Presidencialismo y sistema de partidos en América Latina", en: Mainwaring, Scott y Shugart, Matthew (Comp.), Presidencialismo y Democracia en América Latina (Buenos Aires, Paidós), pp. 255-294.

SUÁREZ CAO, JULIETA (2001): "Innovaciones Constitucionales Provinciales: los casos de San Luis y Tucumán", en: V Congreso Nacional de Ciencia Política Sociedad Argentina de Análisis Político, 14-17 de Nov. (Argentina).

(2011): “¿Federal en teoría pero unitaria en la práctica? Una discusión sobre el federalismo y la provincialización de la política en Argentina", en: Revista SAAP (Vol. 5, № 2, noviembre), pp. 305-321.

Tommasi, Mariano y SPILler, Pablo (DIRS). (2000): Las Fuentes Institucionales del Desarrollo Argentino. Hacia una Agenda Institucional (Buenos Aires, CEDI, Fundación Gobierno y Sociedad).

TSebelis, GeOrge y AlemÁn, EduARdo (2007): "Poderes de agenda condicionales en América Latina", en: Revista PostData (№ 12, agosto), pp. 77-106.

\section{JURISPRUDENCIA CITADA}

\section{Ciudad Autónoma de Buenos Aires:}

SUPERIOR TRIBUNAL DE JUSticIA DE ENTRE Ríos, Fallo "Bertoli, Aurelia T. y otro c/ Caja de Jubilaciones y Pensiones de la Provincia de Entre Rios", del 20/9/1997, en LL, Litoral 1998-2:396.

Superior TRIBunal de JustiCia de la provinCIA de Corrientes, fallos "Cardozo de Colombo, Amanda c/ Provincia de Corrientes" (del 15/4/1998).

SUPERIOR TRIBUNAL DE JUSTICIA DE LA PROVINCIA DE CORRIENTES, fallos "Ledebur, Enrique L. c. Instituto de Prevision Social y/u otro" (del 21/9/1998).

Fiscalía General Adjunta, Dictamen N 28 (Del 25/01/2017) en causa "Rachid, María de la Cruz y otros c/ GCBA sobre Amparo (art. 14 CCABA)".

Juzgado en lo Contencioso Administrativo y TRIBUtaRio N 2 de la CABA, Fallo "Rachid, María de la Cruz y otros c/ GCBA sobre Amparo (art. 14 CCABA)", del 05/07/2013.

CÁmARA de APELACIONES En lo CONTENCIOSO AdMinistrativo y TRIBUtARIO de LA CABA, Resolución de fecha 29 de diciembre de 2015 en autos "Rachid, María de la Cruz y otros c/ GCBA sobre Amparo (art. 14 CCABA)".

PROVINCIA DE BUENOS AIRES:

Suprema Corte de la provincia de Buenos Aires, Causa "Coronel, Oscar Adolfo y otros c/Municipalidad de Navarro s/Demanda contencioso administrativa" del 18/05/1999. 
Suprema Corte de la provincia de Buenos AiRes, Causa "Fiscal de Estado c/Provincia de Buenos Aires (Poder Ejecutivo) s/Demanda contencioso administrativa" del 18/02/2004 e "Iberargen S.A. c/Instituto Provincial de Lotería y Casino s/Amparo" del 01/12/2004.

Suprema Corte de la provincia de Buenos Aires, Causa "Rodríguez, Jorge Orlando c/ Fisco de la Provincia de Buenos Aires y otro/a s/ pretensión anulatoria - empl. Público" del 11/11/2011.

\section{PROVINCIA DE CóRDOBA:}

TRIBUNAL SUPERIOR DE JUSTICIA DE LA PROVINCIA DE CóRdOBA “Fernández, Raúl E. y otros c/ Provincia de Córdoba" (Auto Nro. 30/2002).

Cámara Contencioso administrativa de Segunda nominación, Provincia de Córdoba, Causa "Cura, Norberto Julián y otro c/ Provincia de Córdoba" (Auto Nro. 40/2002).

Cámara de Apelaciones en lo Civil y Comercial de Octava Nominación de la Provincia de Córdoba, "Vexenat, Juan C. y otros c/ DIPAS", Resolución del 12/04/2002.

Cámara Contencioso administrativa de Primera nominación, Provincia de Córdoba, Causa "Bringas, Nicolás c/ Provincia de Córdoba", Resolución del 24/04/2002.

Cámara de Apelaciones en lo Civil y Comercial de Primera nominación, Provincia de Córdoba, Causa "Córdoba, Carlos A. c/ Provincia de Córdoba", fallo del 08/03/2002.

Cámara de Apelaciones en lo Civil y Comercial de Sexta nominación, Provincia de Córdoba, Causa "Toranzo, Juana V. c. Acevedo, Néstor R. y otra", fallo del 09/06/2002.

\section{PROVINCIA DE JUJUY:}

TRIBUNAL SUPERIOR DE JUSTICIA DE JUJUY, Fallo "Condori, Elba Margarita V Estado Provincial" Resolución del 15/04/1993.

TRIBUNAL SUPERIOR DE JUSTICIA DE JUJUY, Fallo "Arroyo de Heredia, María c/ Estado Provincial" Resolución del 05/05/1993.

TRIBUNAL SUPERIOR DE JUSTICIA DE JUJUY, Fallo "Cardozo, Teresa Amalia v. Rivero, Juan Braulio y Estado Provincial", Resolución del 27/12/1994.

TRIBUNAL SUPERIOR DE JUSTICIA DE JUJUY, Fallo “Morales, Gerardo Rubén y otro v. Estado Provincial”, Resolución del 14/3/1995.

TRIBUNAL SUPERIOR DE JUSTICIA DE JUJUY, Fallo "Pasquine, Enrique Guillermo v. Estado Provincial", Resolución del 27/12/1996.

TRIBUnAl SUPERIOR DE JUSTICIA DE JUJUY, Fallo "Vázquez, Pedro Emilio v. Municipalidad de El Talar", Resolución del 13/10/1998.

TRIBUNAL SUPERIOR DE JUSTICIA DE JUJUY, Fallo "Centro de Docentes de enseñanza media y superior c/ Provincia de Jujuy" 16/05/2003.

\section{PROVINCIA DE MENDOZA:}

Suprema Corte de Justicia de la Provincia de Mendoza, Sala I, "Suchetti, Guillermo c/ Empresa Autotransportes Los Andes S. A." del 03/03/2000, LLGran Cuyo 2000, 345 • AR/JUR/3621/2000.

Suprema Corte de Justicia de la Provincia de Mendoza, "Cámara de comercio Industrial y Agropecuario de San Rafael c. Estado Nacional" (dictado el 8/3/2004, Publicado en: L.L GRAN CUYO 2004, cita online/JUR/618/2004). 


\section{NORMAS JURÍDICAS CITADAS}

\section{CONSTITUCIONES:}

CONSTITUCIÓN DE LA NACIÓN ARGENTINA. Texto 1853/1860 con las reformas de 1994.

Constitución de la Provincia de Buenos Aires. 1994.

CONSTITUCión de La Provincia de Catamarca. 1988.

CONSTITUCIÓN DE LA PROVINCIA DE CHACO. 1994.

CONSTITUCIÓN de LA PROVINCIA dE CHUBUt. 1994.

Constitución de LA PRovincia de Córdoba. 2001.

CONSTITUCIÓN dE LA PRovinCIA dE CORRIENTES. 2007.

Constitución de la Provincia de Entre Ríos. 2008.

CONSTITUCIÓN DE LA PROVINCIA DE FoRMOSA. 2003.

CONSTITUCIÓN DE LA PROVINCIA DE JUJUY. 1986.

Constitución de la ProvinCia de LA PAMPA. 1994.

Constitución de la PROVINCIA de LA RiOJa. 2008.

Constitución de la Provincia de Mendoza. 1916.

ConstituCión de LA PROVINCIA de MISIONES. 1958.

Constitución de LA PRovincia de Neuquén. 2006.

Constitución de la PRovincia de Río Negro. 1988.

Constitución de la Provincia de Salta. 2003.

Constitución de LA Provincia de SAN JUAN. 1986.

ConstituCión de LA PROVINCIA de SAN LUIS. 1987.

Constitución de la Provincia de SANTA CRUZ. 1998.

Constitución de LA PROVInCIA de SANTA Fe. 1962.

Constitución de la Provincia de SANtiago del Estero. 2005.

Constitución de la Provincia de Tierra del Fuego, Antártida e IsLas del Atlántico Sur. 1991.

CONSTITUCIÓN DE LA PROVINCIA DE TUCUMÁN. 2006.

Estatuto Organizativo de la Ciudad Autónoma de Buenos Aires. 1996.

\section{LEYES Y DECRETOS:}

Ley N³ 340, Código Civil de La NACIÓn ARgentina. 25 de septiembre de 1869.

LEY N² 26.994, Código CIVIL Y COMERCIAL DE LA NACIÓN ARGENTINA. Boletín Oficial, 08 de octubre de 2014 (con entrada en vigencia el 01 de agosto de 2015 por disposición de la Ley 27.077, Boletín Oficial, 19 de diciembre de 2014).

Provincia de CóRdoba, DeCRETO De NeCESIDAd y URGenCiA № 2555/2006, por medio del cual se autorizaba al Ministerio de Seguridad a ejercer las atribuciones previstas por la Ley 13.409, hasta 
tanto la Legislatura sancione el proyecto de ley que declare el estado de emergencia. 25 de junio de 2006.

PRovinCIA de CóRDoba, DeCRETO de NeCESIDAD y URGENCIA N 40/2007 sobre políticas de seguridad vial. 03 de septiembre de 2007.

Provincia de Córdoba, Ley 13.704, Ratifica DeCReto de NeCesidad y URGenCia Nº 2555/2006. 08 de octubre de 2006.

PROVINCIA DE SAN LUIS, DECRETO N 115-MHP-11 sobre incremento salarial para los empleados públicos provinciales. 22 de febrero de 2011.

PROVINCIA DE SAN LUIS, DECRETO N² 2884 MGJYC 09, sobre la restitución de tierras en propiedad al Pueblo originario Ranquel. 27 de julio de 2009.

Provincia de SAN LUIS, LEy № V-0677-2009, RATIFICA DeCRETO № 2884 MGJyC 09. 29 de julio de 2009.

PROVINCIA DE SAN LUIS, LEY № XV-0757-2011, RATIFICATORIA DEL DECRETO № 115-MHP-11. 29 de junio de 2011. 


\section{Gráficos y Tablas}

GRÁFICO 1: Facultades de Colegislación

\section{Poderes de Decreto}

\section{a. Autónomos}

b. De promulgación

c. Reglamentarios

2. Poder de veto

Poderes

3. Promulgación Parcial

4. DNU reactivos

\section{Iniciativa exclusiva}

6. Trámite urgente

Poderes

Facultades

de

\section{Colegislación}

Fuente: elaboración propia.

Tabla 1: Promulgación y publicación de las leyes

\begin{tabular}{|c|c|c|c|c|c|}
\hline & $\begin{array}{c}\begin{array}{c}\text { Promulgación } \\
\text { tácita }\end{array} \\
\end{array}$ & Plazo & Plazo publicación & $\begin{array}{c}\text { Publicación por } \\
\text { la legislatura }\end{array}$ & Plazo \\
\hline 2. $\mathrm{CABA}$ & Art. 86 & 10 días & - & Sí & \\
\hline 4. $\mathrm{CHA}$ & Art. 118 & 10 días & Día inmediato posterior & Sí & 10 días hábiles \\
\hline 5. $\mathrm{CHU}$ & Art. 140 & 10 días & - & No & \\
\hline 6. $\mathrm{CBA}$ & Art. 200 & 10 días & - & No & \\
\hline 8. $\quad$ ER & Art. $130,2^{\circ}$ párr. & 8 días & - & Sí & \\
\hline 9. $\mathrm{FOR}$ & Art. 124 & 10 días & - & No & \\
\hline 10. JU & Art. 120 & 10 días & 10 días hábiles de su promulgación. & Sí & \\
\hline 11. LP & Art. 70 & 10 días & - & No & \\
\hline 12. LR & Art. 107 & 10 días & - & No & \\
\hline 13. MZA & Art. 101 & 10 días & - & No & \\
\hline 18. SJ & Art. 170 & 10 días & - & $\mathrm{No}$ & \\
\hline 19. SL & Art. 170 & 10 días & 10 días de recibido & No & \\
\hline 20. SC & Art. 106 & 16 días & Día inmediato posterior & Sí & \\
\hline 21. SF & & & 8 días de promulgadas & Sí & \\
\hline 22. SE & Art. 135 & 10 días & - & No & \\
\hline 23. TF & Art. 108 & 10 días & - & No & \\
\hline 24. TU & Art. 71 & 10 días & - & $\mathrm{No}$ & \\
\hline
\end{tabular}


Tabla 2: Regulación de los DNU en las constituciones provinciales

\begin{tabular}{|c|c|c|c|c|c|c|}
\hline & \multirow[t]{2}{*}{$\mathbf{C P}$} & \multirow[t]{2}{*}{$\begin{array}{l}\text { Acuerdo } \\
\text { ministros }\end{array}$} & \multirow[t]{2}{*}{ Materias excluidas } & \multicolumn{2}{|c|}{$\begin{array}{l}\text { Conval. por } \\
\text { legislatura }\end{array}$} & \multirow[t]{2}{*}{$\begin{array}{l}\text { Efectos del silencio } \\
\text { de la Legislatura }\end{array}$} \\
\hline & & & & & Plazo & \\
\hline 1. CABA & Art. 103 & Sí & $\begin{array}{l}\text { - Procesal penal } \\
\text { - Tributaria } \\
\text { - Electoral } \\
\text { - Partidos políticos }\end{array}$ & Sí & & No dice \\
\hline 2. CHA & $\begin{array}{l}\text { Art. } 141, \\
\text { inc. } 18 \quad \mathrm{y} \\
142\end{array}$ & Sí & - & Sí & & No dice \\
\hline 3. CHU & Art. 156 & Sí & - & Sí & 30 días & Pierde efectos jurídicos \\
\hline 4. LR & $\begin{array}{l}\text { Art. } 126 \text {, } \\
\text { inc. } 12\end{array}$ & Sí & $\begin{array}{l}\text { - Tributaria } \\
\text { - Electoral } \\
\text { - Intervención a municipios }\end{array}$ & Sí & 30 días & Queda convertido en ley \\
\hline 5. RN & $\begin{array}{l}\text { Art. 181, } \\
\text { inc. } 6\end{array}$ & Sí & - & Sí & 90 días & Queda convertido en ley \\
\hline 6. SA & Art. 145 & Sí & - & Sí & 90 días & Queda convertido en ley \\
\hline 7. SJ & $\begin{array}{l}\text { Art. } 157 \mathrm{y} \\
189, \text { inc. } 17\end{array}$ & - & $\begin{array}{l}\text { - Decisiones legislativas } \\
\text { - Leyes de base o programas legislativos } \\
\text { - Derechos, deberes y garantías constitucionales } \\
\text { - Tributos } \\
\text { - Crear/suprimir empleos no previstos por la } \\
\text { Constitución } \\
\text { - Expropiaciones } \\
\text { - Subsidios a las municipalidades }\end{array}$ & Sí & 30 días & Queda convertido en ley \\
\hline 8. SE & Art. 158 & Sí & $\begin{array}{l}\text { - Tributaria } \\
\text { - Electoral } \\
\text { - Partidos políticos. }\end{array}$ & Sí & 20 días & No dice \\
\hline 9. TU & $\begin{array}{l}\text { Art. } 101, \\
\text { inc. } 2\end{array}$ & - & $\begin{array}{l}\text { - Tributaria } \\
\text { - Electoral } \\
\text { - Partidos políticos }\end{array}$ & Sí & & Queda convertido en ley \\
\hline
\end{tabular}

Fuente: Elaboración propia en base a constituciones provinciales

GRÁFICO 2: Clasificación del poder de veto del ejecutivo de acuerdo al tipo de insistencia parlamentaria y el formato de la legislatura

\begin{tabular}{|c|c|c|}
\hline & Absoluta & $2 / 3$ \\
\hline Bicameral & Fuerte & Muy fuerte \\
\hline Unicameral & Muy débil & Débil \\
\hline
\end{tabular}

Fuente: elaboración propia. 
Tabla 3: Poder de veto vs Insistencia parlamentaria

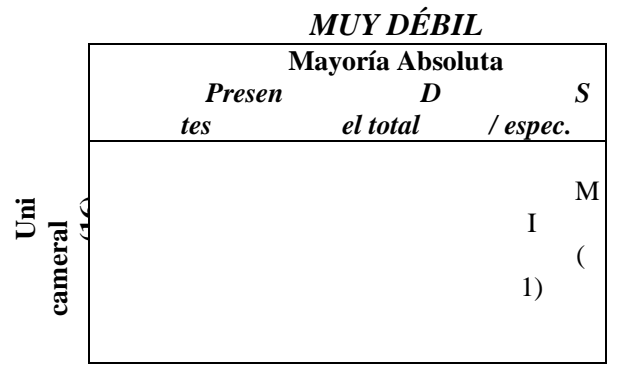

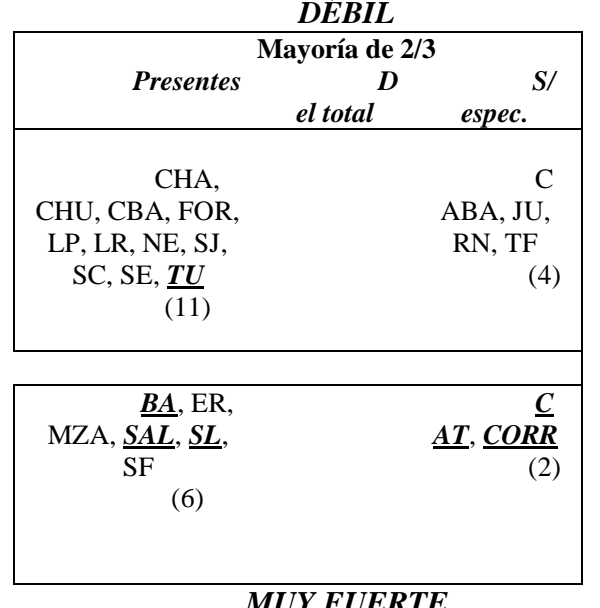

FUERTE

MUY FUERTE

Fuente: elaboración propia.

Tabla 4: Promulgación parcial en las constituciones provinciales

\begin{tabular}{|c|c|c|c|c|c|c|}
\hline & \multirow[t]{2}{*}{$\begin{array}{c}\text { Promul. } \\
\text { parcial }\end{array}$} & \multirow[t]{2}{*}{ Art. } & \multirow[t]{2}{*}{$\begin{array}{l}\text { Requisito } \\
\text { de unidad }\end{array}$} & \multicolumn{2}{|c|}{$\begin{array}{l}\text { Consentimiento } \\
\text { de la Legislatura }\end{array}$} & \multirow[t]{2}{*}{$\begin{array}{l}\text { Materia o } \\
\text { tipo de ley }\end{array}$} \\
\hline & & & & & $\begin{array}{c}\text { Mayorí } \\
\text { a }\end{array}$ & \\
\hline BA & Sí & Art. 108 & No & No & - & Presupuesto \\
\hline $\mathrm{CABA}$ & Sí & Art. 88 & No & Sí & No dice & Todas \\
\hline CAT & Sí & Art. 188 & No & No & - & Presupuesto \\
\hline CHA & Sí & Art. 118 & No & No & - & Presupuesto \\
\hline $\mathrm{CHU}$ & Sí & Art. 142 & Sí & Sí & $\begin{array}{l}2 / 3 \\
\text { miem. }\end{array}$ & Todas \\
\hline CBA & Sí & Arts. 144 inc. 5,109 & $\mathrm{Si}$ & Sí & No dice & Todas \\
\hline CORR & Sí & Art. 122 & No & No & - & Presupuesto + impuesto \\
\hline ER & Sí & Art. 129 & Sí & No & - & Todas \\
\hline FOR & Sí & Art. 125 & Sí & No & - & Todas \\
\hline $\mathrm{JU}$ & Sí & Art. 121 & No & No & - & Presupuesto \\
\hline LP & $\mathrm{Si}$ & Art. 70 & No & No & - & Presupuesto + impuesto \\
\hline LR & Sí & Art. 107 & No & No & - & Todas \\
\hline MZA & Sí & Art. 102 & No & No & - & Presupuesto + impuesto \\
\hline MI & Sí & Art. 104 & No & No & - & Presupuesto \\
\hline $\mathrm{NE}$ & Sí & Art. 195 & No & Sí & $\begin{array}{l}\text { May. } \\
\text { Simp. }\end{array}$ & Todas + Presupuesto \\
\hline $\mathrm{RN}$ & Sí & Art. 146 & No & No & - & Presupuesto \\
\hline SA & Sí & Art. 144 & Sí & No & - & Todas \\
\hline SJ & $\mathrm{Si}$ & Art. 169 & Sí & Sí & No dice & Todas * \\
\hline SL & Sí & Arts. 135 y 136 & Sí & No & - & Todas + Presupuesto \\
\hline SC & Sí & Art. 107 & No & No & - & Todas \\
\hline SF & Sí & Art. 59 & No & Sí & $\begin{array}{l}\text { May. } \\
\text { Simp. }\end{array}$ & Todas + Presupuesto \\
\hline SE & Sí & (Art. 135) & Sí & Sí & No dice & Todas \\
\hline TF & $\mathrm{Si}$ & Art. 110 & Sí & Sí & No dice & Todas \\
\hline TU & $\mathrm{Si}$ & Art. 71 & Sí & No & & Todas + Presupuesto \\
\hline
\end{tabular}

* Con excepción de dos tipos de leyes que no pueden ser vetadas.

Fuente: Elaboración propia en base a constituciones provinciales 


\begin{tabular}{|c|c|c|c|c|}
\hline \multicolumn{5}{|c|}{ Tabla 5: Iniciativa exclusiva del ejecutivo } \\
\hline & Presupuesto & Ministerios & $\begin{array}{l}\text { Trámite } \\
\text { urgente }\end{array}$ & Otras \\
\hline 1. $\mathbf{B A}$ & Art. 103 inc. 2 & & & \\
\hline 2. CABA & & Art. 100 & & - Plan Urbano Ambiental (Art. 81 inc. 4) \\
\hline 3. CAT & Art. 149 inc. 6 & & & \\
\hline 4. CHA & Art. 141 inc. 8 & & - Art. 117 & \\
\hline 5. CHU & Art. 156 inc. 12 & & - Art. 144 & \\
\hline 6. $\quad$ CBA & Art. 144 inc. 3 & Art. 144 inc. 3 & & \\
\hline 7. CORR & Art. 162 inc. 15 & & & \\
\hline 8. $\quad$ ER & Art. 175 inc. 8 & & & \\
\hline 9. $\quad$ FOR & Art 142 inc. 6 & & & \\
\hline 10. JU & & & & - Ley Orgánica PE y Entes descentr. (Art 137 inc. 3) \\
\hline 11. LP & Art 81 inc. 6 & & & - Leyes de Impuestos (Art 81 inc. 6) \\
\hline 12. LR & Art 126 inc. 5 & Art 126 inc. 5 & & \\
\hline 13. MZA & Art 128 inc. 14 & & & \\
\hline 14. MI & Art 116 inc. 4 & & & \\
\hline 15. NE & Art 214 inc. 8 & & & \\
\hline 16. $\mathrm{RN}$ & Art 181 inc. 11 & & & $\begin{array}{l}\text { - Entes Autárquicos y empresas del Estado (Art } 181 \text { inc. } \\
15 \text { ) }\end{array}$ \\
\hline 17. SA & Art. 144 , inc. 8 & Art. 147 & & \\
\hline 18. SJ & Art. 189 inc. 5 & Art. 191 & & \\
\hline 19. SL & Art. 168 inc. 6 & Art. 130 & & \\
\hline 20. SC & Art. 119 inc. 15 & & & \\
\hline 21. SF & Art. 72 inc. 8 & & & \\
\hline 22. SE & Art. 160 inc. 8 & & & \\
\hline 23. TF & Art. 135 inc. 8 & Art. 136 & & \\
\hline 24. TU & Art. 101 inc. 7 & Art. 102 & & \\
\hline
\end{tabular}

Fuente: Elaboración propia en base a constituciones provinciales

\begin{tabular}{|c|c|c|c|c|c|c|}
\hline \multicolumn{7}{|c|}{ Tabla 6: Trámite de urgente tratamiento } \\
\hline & $\begin{array}{l}\text { Plazo p/ } \\
\text { tratar }\end{array}$ & $\begin{array}{l}\text { Oportunidad } \\
\text { de pedirlo }\end{array}$ & $\begin{array}{l}\text { Posibilidad de } \\
\text { rechazo }\end{array}$ & Materias excluidas & $\begin{array}{c}\text { Límites } \\
\text { cuantitativos }\end{array}$ & $\begin{array}{c}\text { Falta de } \\
\text { tratamiento por } \\
\text { la legislatura }\end{array}$ \\
\hline 1. CHA & 60 días & $\begin{array}{l}\text { después de la } \\
\text { remisión y en } \\
\text { cualquier etapa }\end{array}$ & $\begin{array}{lrr}\text { Con la mitad } & \text { más } \\
\text { uno de los } \\
\text { miembros }\end{array}$ & $\begin{array}{l}\text { - Tributaria } \\
\text { - Electoral } \\
\text { - Presupuesto } \\
\text { - Reglam. de derechos y } \\
\text { garantías constitucionales } \\
\text { - Ref. Constitucionales }\end{array}$ & $\begin{array}{l}\text { No más de } 3 \\
\text { proyectos } \\
\text { simultáneamente }\end{array}$ & $\begin{array}{l}\text { Se tienen por } \\
\text { aprobados }\end{array}$ \\
\hline 2. CHU & 60 días & $\begin{array}{l}\text { después de la } \\
\text { remisión y en } \\
\text { cualquier etapa }\end{array}$ & $\begin{array}{l}\text { Por la mayoría de } \\
\text { sus miembros (con } \\
\text { excepción del } \\
\text { Presupuesto) }\end{array}$ & & & $\begin{array}{l}\text { Se tienen por } \\
\text { aprobados }\end{array}$ \\
\hline \multirow[t]{2}{*}{ 3.SL } & 60 días & \multirow{2}{*}{$\begin{array}{l}\text { después de su } \\
\text { remisión y en } \\
\text { cualquier etapa }\end{array}$} & \multirow{2}{*}{$\begin{array}{l}\text { Con los } 2 / 3 \text { de los } \\
\text { miembros }\end{array}$} & \multirow[t]{2}{*}{ Ley de Presupuesto } & & \multirow{2}{*}{$\begin{array}{l}\text { Se tienen por } \\
\text { aprobados }\end{array}$} \\
\hline & $\begin{array}{l}\text { 30 días } \\
(15 \text { para } \\
\text { cada } \\
\text { Cámara) } \\
\end{array}$ & & & & & \\
\hline 4. TF & 30 días & $\begin{array}{l}\text { después de } \\
\text { envío y } \\
\text { cualquier etapa }\end{array}$ & $\begin{array}{lr}\text { Sin especificar } \\
\text { mayoría } & \text { (con } \\
\text { excepción } & \text { del } \\
\text { Presupuesto) } & \\
\end{array}$ & & & $\begin{array}{l}\text { Se tienen por } \\
\text { aprobados }\end{array}$ \\
\hline
\end{tabular}

Fuente: Elaboración propia en base a constituciones provinciales 
Tabla 7: Índice sobre los Poderes de Legislación en el constitucionalismo subnacional argentino.

\begin{tabular}{|c|c|c|c|c|c|c|c|c|c|c|c|c|c|c|}
\hline & 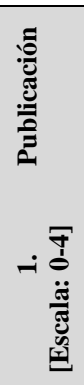 & 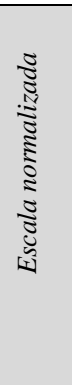 & 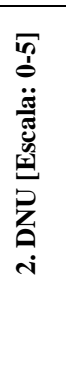 & 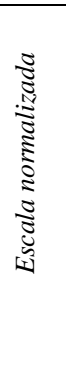 & 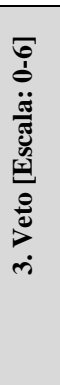 & 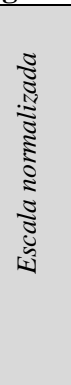 & 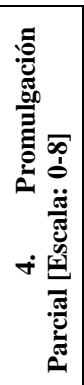 & 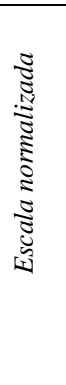 & 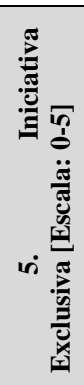 & 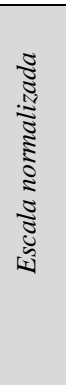 & 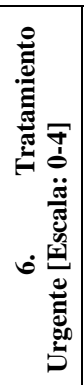 & 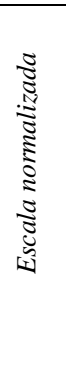 & 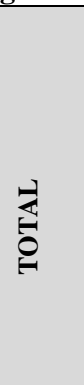 & 良 \\
\hline BA & 2 & 0,50 & 0 & 0,00 & 6 & 1,00 & 1 & 0,13 & 2 & 0,40 & 0 & 0,00 & 11 & 2,03 \\
\hline CABA & 2 & 0,50 & 2 & 0,40 & 5 & 0,83 & 6 & 0,75 & 1 & 0,20 & 0 & 0,00 & 16 & 2,68 \\
\hline CAT & 2 & 0,50 & 0 & 0,00 & 6 & 1,00 & 1 & 0,13 & 2 & 0,40 & 0 & 0,00 & 11 & 2,03 \\
\hline CHA & 1 & 0,25 & 4 & 0,80 & 5 & 0,83 & 1 & 0,13 & 5 & 1,00 & 1 & 0,25 & 17 & 3,26 \\
\hline $\mathrm{CHU}$ & 4 & 1,00 & 1 & 0,20 & 5 & 0,83 & 3 & 0,28 & 5 & 1,00 & 2 & 0,50 & 20 & 3,81 \\
\hline CBA & 4 & 1,00 & 0 & 0,00 & 5 & 0,83 & 5 & 0,63 & 3 & 0,60 & 0 & 0,00 & 17 & 3,06 \\
\hline CORR & 4 & 1,00 & 0 & 0,00 & 6 & 1,00 & 2 & 0,25 & 2 & 0,40 & 0 & 0,00 & 14 & 2,65 \\
\hline ER & 2 & 0,50 & 0 & 0,00 & 6 & 1,00 & 7 & 0,88 & 2 & 0,40 & 0 & 0,00 & 17 & 2,78 \\
\hline FOR & 4 & 1,00 & 0 & 0,00 & 5 & 0,83 & 7 & 0,88 & 2 & 0,40 & 0 & 0,00 & 18 & 3,11 \\
\hline JU & 1 & 0,25 & 0 & 0,00 & 5 & 0,83 & 1 & 0,13 & 1 & 0,20 & 0 & 0,00 & 8 & 1,41 \\
\hline$\overline{L P}$ & 4 & 1,00 & 0 & 0,00 & 5 & 0,83 & 2 & 0,25 & 4 & 0,80 & 0 & 0,00 & 15 & 2,88 \\
\hline $\begin{array}{l}\text { LR } \\
\end{array}$ & 4 & 1,00 & 3 & 0,60 & 5 & 0,83 & 8 & 1,00 & 3 & 0,60 & 0 & 0,00 & 23 & 4,03 \\
\hline MZA & 4 & 1,00 & 0 & 0,00 & 6 & 1,00 & 2 & 0,25 & 2 & 0,40 & 0 & 0,00 & 14 & 2,65 \\
\hline MI & 1 & 0,25 & 0 & 0,00 & 3 & 0,50 & 1 & 0,13 & 2 & 0,40 & 0 & 0,00 & 7 & 1,28 \\
\hline $\mathrm{NE}$ & 4 & 1,00 & 0 & 0,00 & 5 & 0,83 & 4 & 0,50 & 2 & 0,40 & 0 & 0,00 & 15 & 2,73 \\
\hline RN & 2 & 0,50 & 5 & 1,00 & 5 & 0,83 & 1 & 0,13 & 3 & 0,60 & 0 & 0,00 & 16 & 3,06 \\
\hline SA & 3 & 0,75 & & 1,00 & & 1,00 & & 0,88 & & 0,60 & & 0,00 & 24 & 4,23 \\
\hline SJ & 4 & 1,00 & & 0,60 & & 0,83 & & 0,63 & & 0,60 & & 0,00 & 20 & 3,66 \\
\hline SL & 3 & 0,75 & & 0,00 & & 1,00 & & 0,88 & & 0,60 & & 1,00 & 23 & 4,23 \\
\hline SC & 1 & 0,25 & & 0,00 & & 0,83 & & 1,00 & & 0,40 & & 0,00 & 16 & 2,48 \\
\hline SF & 1 & 0,25 & & 0,00 & & 1,00 & & 0,50 & & 0,40 & & 0,00 & 13 & 2,15 \\
\hline SE & 4 & 1,00 & & 0,40 & & 0,83 & & 0,63 & & 0,40 & & 0,00 & 18 & 3,26 \\
\hline $\mathrm{TF}$ & 4 & 1,00 & & 0,00 & & 0,83 & & 0,63 & & 0,60 & & 0,75 & 20 & 3,81 \\
\hline $\mathrm{TU}$ & 4 & 1,00 & & 0,60 & & 0,83 & & 0,88 & & 0,60 & & 0,00 & 22 & 3,91 \\
\hline Prom. & 2,88 & $\mathbf{0 , 7 2}$ & 1,17 & $\mathbf{0 , 2 3}$ & 5,25 & $\mathbf{0 , 8 7}$ & 4,17 & $\mathbf{0 , 5 2}$ & 2,58 & 0,52 & 0,42 & $\mathbf{0 , 1 0}$ & 16,46 & 2,97 \\
\hline FEDERAL & 4 & 1,00 & & 0,40 & & 1,00 & & 0,63 & & 0,00 & & 0,00 & 19 & 3,03 \\
\hline
\end{tabular}

Referencias para la Tabla 7:

* $0=$ Sin poder de promulgación y publicación; $1=$ Con facultad de publicar, pero dentro de un determinado plazo, vencido el cual, la Legislatura puede publicar la ley; 2 = Con facultad de publicar, sin plazo, y la Legislatura puede publicar la ley; $3=$ Con facultad de publicar dentro de un determinado plazo, pero la Legislatura no tiene facultad de publicar la ley; 4 = Con facultad de publicar, sin plazo, y la Legislatura no tiene facultad de publicar la ley.

** 0 = Carece de la facultad de emitir DNU, y la Constitución o bien prohíbe o bien no hace referencia a esta facultad; $1=$ La Constitución reconoce la facultad de emitir DNU, pero excluye ciertas materias, con convalidación de la legislatura so pena de perder efectos jurídicos; 2 = La Constitución reconoce la facultad de emitir DNU, pero excluye ciertas materias, con convalidación de la legislatura aunque sin establecer los efectos de su silencio; 3 = La Constitución reconoce la facultad de emitir DNU, pero excluye ciertas materias, con convalidación de la legislatura, ante cuyo silencio el decreto se convierte en ley; 4 = La Constitución reconoce la facultad de emitir DNU, sin excluir materias, con convalidación de la legislatura aunque sin establecer los efectos de su silencio; 5 = La Constitución reconoce la facultad de emitir DNU, sin excluir materias, con convalidación de la legislatura, ante cuyo silencio el decreto se convierte en ley.

$* * * 0=$ Sin poder de veto; 1 = Veto revocado con el voto de la mayoría de los miembros presentes en la cámara única; $2=$ Veto revocado con el voto de la mayoría de los miembros presentes de cada cámara; 3 = Veto revocado con el voto de la mayoría del total de miembros de la cámara única; 4 = Veto revocado con el voto de la mayoría del total de miembros de cada cámara; $5=$ Veto revocado con el voto de $2 / 3$ de los miembros de la cámara única; $6=$ Veto revocado con el voto de $2 / 3$ de los miembros en cada cámara.

**** $0=$ Sin facultad de promulgación parcial; 1 = Con posibilidad de promulgación parcial solo respecto del presupuesto; 2 = Con posibilidad de promulgación parcial solo respecto del presupuesto y otras áreas acotadas de políticas (impuestos); $3=$ Con posibilidad de promulgación parcial respecto del presupuesto y sobre cualquier tipo de ley, pero con requisito de unidad normativa y consentimiento de la legislatura de 2/3; $4=$ Con posibilidad de promulgación parcial respecto del presupuesto y sobre cualquier tipo de ley, pero con requisito de unidad normativa y consentimiento de la legislatura con mayoría simple; $5=$ Con posibilidad de promulgación parcial respecto del presupuesto y sobre cualquier tipo de ley, pero con requisito de unidad normativa y consentimiento de la legislatura con mayoría sin especificar; 6 = Con posibilidad de promulgación parcial respecto del presupuesto y sobre cualquier tipo de ley, sin requisito de unidad normativa y consentimiento de la legislatura con mayoría sin especificar; 7 = Con posibilidad de promulgación parcial respecto del presupuesto y sobre cualquier tipo de ley, con requisito de unidad normativa y sin consentimiento de la legislatura; 8 = Con posibilidad de promulgación parcial respecto del presupuesto y sobre cualquier tipo de ley, sin requisito de unidad normativa y sin consentimiento de la legislatura.

***** $0=$ Sin facultad de iniciativa exclusiva; 1 = Con facultad de iniciativa exclusiva sobre áreas acotadas (no incluye presupuesto), pero el legislativo tiene facultades para modificar la legislación; 2 = Con facultad de iniciativa exclusiva solo en materia de presupuesto, pero el legislativo tiene facultades para modificar la legislación; $3=$ Con facultad de iniciativa exclusiva en materia de presupuesto y sobre otras áreas acotadas, pero el legislativo tiene facultades para modificar la legislación; $4=$ Con facultad de iniciativa exclusiva en materia presupuestaria y sobre impuestos, pero el legislativo tiene facultades para modificar la legislación; 5 
= Con facultad de iniciativa exclusiva solo en materia de presupuesto, con posibilidad de imprimir trámite de urgente tratamiento, pero el legislativo tiene facultades para modificar la legislación.

$* * * * * * 0=$ Sin facultad de imprimir trámite de urgente tratamiento; 1 = Con facultad de imprimir trámite de urgente tratamiento con un plazo de 60 días, pero con un límite cuantitativo y con ciertas áreas excluidas, pudiendo ser rechazado por la mitad más uno de los miembros de la Legislatura; 2 = Con facultad de imprimir trámite de urgente tratamiento con un plazo de 60 días, sin límite cuantitativo y sin áreas excluidas, pudiendo ser rechazado por la mitad más uno de los miembros de la Legislatura; 3 = Con facultad de imprimir trámite de urgente tratamiento con un plazo de 60 días, sin límite cuantitativo y sin áreas excluidas, pudiendo ser rechazado por la Legislatura sin especificar mayorías; 4 = Con facultad de imprimir trámite de muy urgente tratamiento con un plazo de 15 días para cada cámara, sin límite cuantitativo y sin áreas excluidas (salvo presupuesto), pudiendo ser rechazado por los 2/3 de los miembros de la Legislatura.

Fuente: Elaboración propia en base a PNUD 2004:77. 